\title{
Article \\ Statistical Approach to Potentially Enhance the Postbiotication of Gluten-Free Sourdough
}

\author{
Bogdan Păcularu-Burada ${ }^{1}$ (D), Mihaela Turturică ${ }^{1}$, João Miguel Rocha ${ }^{2}$ (D) and Gabriela-Elena Bahrim ${ }^{1, *(D)}$ \\ 1 Faculty of Food Science and Engineering, Dunarea de Jos University of Galati, Domneasca Street No. 111, \\ 800201 Galati, Romania; bogdan.pacularu@ugal.ro (B.P.-B.); mihaela.turturica@ugal.ro (M.T.) \\ 2 REQUIMTE-Chemistry and Technology Network, Green Chemistry Laboratory (LAQV), Department of \\ Chemistry and Biochemistry, Faculty of Sciences from University of Porto (FCUP), Rua do Campo Alegre, \\ P-4169-007 Porto, Portugal; jrocha@sourdomics.com or jmfrocha@fc.up.pt \\ * Correspondence: gabriela.bahrim@ugal.ro; Tel.: +40-336-130-182
}

Citation: Păcularu-Burada, B.; Turturică, M.; Rocha, J.M.; Bahrim, G.-E. Statistical Approach to

Potentially Enhance the Postbiotication of Gluten-Free Sourdough. Appl. Sci. 2021, 11, 5306. https://doi.org/10.3390/app11115306

Academic Editors: Roberto Nigro and Anabela Raymundo

Received: 21 April 2021

Accepted: 3 June 2021

Published: 7 June 2021

Publisher's Note: MDPI stays neutral with regard to jurisdictional claims in published maps and institutional affiliations.

Copyright: (c) 2021 by the authors. Licensee MDPI, Basel, Switzerland. This article is an open access article distributed under the terms and conditions of the Creative Commons Attribution (CC BY) license (https:// creativecommons.org/licenses/by/ $4.0 /)$.
Featured Application: This optimized gluten-free sourdough is suitable for utilization as a functional ingredient in gluten-free bakery recipes. The sourdough's production following a controlled fermentation process can increase the predictability of the postbiotic properties of the fermented product. Postbiotics are healthy alternatives to obtain foods with enhanced antimicrobial and technological features.

Abstract: Fermented products are permanently under the attention of scientists and consumers, both due to nutritional importance and health promoting effects. The fermented functional foods contribute to a more balanced diet and increase the immune responses (among many other health effects) with positive implications for quality of life. In this sense, improving the sourdough's fermentation to boost the biotic (postbiotic and paraprobiotic) properties of the sourdough-based products has positive impacts on the nutritional and functional properties of the final baked products. These enhanced sourdoughs can be obtained in controlled fermentation conditions and used as sourdough bread improvers or novel bioingredients. In this context, our work aimed to optimize, using statistical tools, a gluten-free sourdough based on chickpea, quinoa, and buckwheat fermentation with selected lactic acid bacteria (LAB) to enhance its postbiotic properties. The most important biotechnological parameters were selected by Plackett-Burman Design (PBD) and then Response Surface Methodology (RSM) was applied to evaluate the interactions between the selected factors to maximize the gluten-free sourdough's properties. As a result, the optimized fermented sourdough had antimicrobial activity with inhibition ratios between 71 and $100 \%$ against the Aspergillus niger, Aspergillus flavus, Penicillium spp. molds and against the Bacillus spp endospore-forming Gram-positive rods. The optimized variant showed a total titratable acidity (TTA) of $40.2 \mathrm{~mL} \mathrm{NaOH} \mathrm{0.1N}$. Finally, the high-performance liquid chromatography (HPLC) analysis highlighted a heterofermentative profile for the organic acids from the optimized sourdough. Among flavonoids and polyphenols, the level of caffeic and vanillic acids increased after lactic acid fermentation. The comparison between the optimized sourdough and the control evidenced significant differences in the metabolite profiles, thus highlighting its potential postbiotication effect.

Keywords: gluten-free flours; selected lactic acid bacteria; solid state fermentation; sourdough; design of the experiments; optimization; postbiotics

\section{Introduction}

The spontaneous fermentation of flours from cereals, pseudocereals, legumes or flours from their byproducts results in a sourdough-a fermented bread dough typically characterized by acidic taste and aroma, which can be used further to manufacture differentiated bakery products with economic and nutritional added-value [1-3]. Selected lactic acid bacteria (LAB) starters were employed in the sourdough's fermentation to maximize the 
sourdough bread's shelf-life or to enhance the nutritional and functional value [3-5]. The utilization of the metabiotics (including postbiotics and paraprobiotics) to enhance the functional properties of the fermented products represent novel conceptual approaches applied in the food and feed industry that contribute to a healthier lifestyle [6]. Dietary fibers, known also as prebiotics, support the proliferation of probiotics in the colon [7]. Postbiotic compounds (metabolites and/or microbial cells fractions) are usually produced by microorganisms during fermentation, and they have valuable functional and health promoting effects. Additionally, paraprobiotics ("ghost probiotics") are the result of probiotic cells' disruption by different treatments and the exploitation of these products $[8,9]$. The functional and technological features of the sourdoughs depend on various factors, the most important being the metabolic properties of the LAB strains and the fermentation parameters $[3,10,11]$ as well as the treatments applied to the fermented products in order to promote postbiotic and paraprobiotic compounds, e.g., high pressure treatments, ohmic heating, ultrasonication or UV light exposure [12,13]. Freeze-drying or spray-drying were successfully used in sourdough technology $[14,15]$ in order to improve its bioavailability behavior and the reported results concluded that sourdough breads are digested faster compared to leavened baked goods [16], and, moreover, sourdough can contribute towards the reduction in the use of salt in baked goods due to its sour taste [17,18]. The antidiabetic, hypocholesterolemic, antimicrobial and antioxidative effects of postbiotics and paraprobiotics from LAB strains were highlighted in the literature, and this is a research topic that is still being intensively studied $[3,9,19]$. All these strategies supporting sustainability are characterized by a responsible utilization of the available resources to fulfill consumers' expectations and to ensure their well-being. The products manufactured by socially responsible companies that have implemented sustainable policies are frequently chosen by Romanian consumers [20,21].

Chickpea, quinoa and buckwheat are gluten-free raw materials characterized mainly by their complex amino acids composition with a low allergenicity and anticarcinogenic effects. Besides their protein content, quinoa and buckwheat are consumed worldwide due to their contents of fatty acids, vitamins, minerals and antioxidant compounds, molecules that support diverse health benefits [3,22-25]. The nutritional and functional value of these gluten-free seeds can be enhanced by malting, cooking or fermentation [26,27]. Beverages, pasta $[28,29]$, bread and sourdough were successfully made using the above-mentioned pseudocereals and legumes [30-32].

Okara is the main byproduct from the soymilk industry, rich in proteins, fibers and antioxidants. The solid-state fermentation (SSF) of okara with Kluyveromyces marxianus $[33,34]$ or Saccharomyces cerevisiae strains increased the content of soluble dietary fibers and crude fats and decreased the level of antinutritional factors [35]. Moreover, the Lactobacillus plantarum strain increased the antioxidant activity of the fermented okara [36]. Symbiotic products that prevent diabetes and cardiovascular diseases based on okara and Lactobacillus casei were also studied and correlated [37-39].

Experimental designs using the Plackett-Burman Design (PBD) and Response Surface Methodology (RSM) were widely used in research in the biotechnology and food industries [40]. For example, recipes for a sweet bread product [41], and for gluten-free noodles were optimized by RSM [42]. The rheological and textural implications of the replacement of salt or wheat flour with wheat sourdough and pseudocereal flours were determined as well by RSM $[43,44]$.

The aims of this work were to establish the influence of the biotechnological parameters on the fermentation of selected gluten-free flours in controlled solid-state fermentation with selected LAB strains, using the statistical tools (PBD and RSM) for the mathematical modelling and analysis. The optimized parameters were selected with the objective of enhancing the antimicrobial and technological characteristics, from the perspective of the development of assisted bioprocesses which are able to retain the desired postbiotics and to enhance their functional potential. 


\section{Materials and Methods}

\subsection{Materials, Microorganisms and Culture Conditions}

The LAB strains used in this study were previously selected based on specific functional properties, respectively, the acidification capacity, the production of exopolysaccharides and the antimicrobial spectra at different $\mathrm{pH}$ values and temperatures [45]. Specifically, four LAB strains as part of the Microorganisms Collection of Dunărea de Jos University of Galati (acronym MIUG), corresponding to three Lactobacillus spp. strains (coded MIUG BL 21, MIUG BL 24 and MIUG BL 38) and one Leuconostoc spp. strain (coded MIUG BL 40) were tested. The presumptive identification at species level was carried out by Biolog Microbial Identification System (Biolog Inc., Hayward, CA, USA) using 94-well Gen III MicroPlates for aerobes. The manufacturer's instructions were carefully followed, as previously described [46-48]. The LAB strains were presumptively identified as follows: MIUG BL 21 being Lactobacillus paracasei ssp. paracasei; MIUG BL 24 being Lactobacillus parabuchneri; MIUG BL 38 being Lactobacillus brevis and MIUG BL 40 being Leuconostoc mesenteroides ssp. mesenteroides.

The stock cultures of LAB were reactivated in de Man, Rogosa and Sharpe (MRS) broth. After $48 \mathrm{~h}$ of incubation at $37^{\circ} \mathrm{C}$ (Binder BF4000, Tuttlingen, Germany) under aerobiosis, each inoculum was diluted in MRS broth to reach an optical density at the wavelength of $600 \mathrm{~nm}\left(\mathrm{OD}_{600 \mathrm{~nm}}\right)$ of 2.0, using a spectrophotometer (Libra S22 UV-VIS, Biochrom, Cambridge, UK) [49]. The cell viable counts of LAB in each inoculum was also determined using saline $(0.9 \%, w / v)$ serial dilutions inoculated in MRS agar plates [50,51]. For the established optical density $(2.0$ at $\lambda=600 \mathrm{~nm})$ and incubation conditions ( $48 \mathrm{~h}$, $37^{\circ} \mathrm{C}$, aerobiosis), an inoculum size of ca. $1 \times 10^{7}$ colony-forming units per milliliter $(\mathrm{CFU} / \mathrm{mL})$ was obtained for all LAB strains. The mold strains used in this study as the indicator microorganisms for the antifungal effect were isolated and purified as reported in our previous work [45]. Prior to their use, the stock cultures of Aspergillus niger, Aspergillus flavus and Penicillium spp. strains were reactivated on Potato Glucose agar (PGA) slants at $25^{\circ} \mathrm{C}$ (Pol-Eko Aparatura, Poland) for $96 \mathrm{~h}$ under aerobiosis. The indicator microorganism used for the antibacterial activity was a Bacillus spp. strain previously isolated from quinoa seeds, as reported elsewhere [45]. This bacterial strain was routinely reactivated from stock cultures by cultivation overnight on Nutrient broth at $37^{\circ} \mathrm{C}$ under aerobiosis.

Whole seeds of chickpea, white quinoa, buckwheat, and non-genetically modified soybeans were purchased from Solaris Plant S.R.L, Bucharest, Romania. The seeds were finely ground with a coffee mill for approximately 5-7 min (DeLonghi, Bucharest, Romania), and the respective flours were further used for the experiments in this study. The soybeans were previously soaked in tap water for $12 \mathrm{~h}$ at room temperature. Afterwards, soymilk was obtained from the soaked beans and water 1:4 $(w / v)$ using a blender (Bosch, Cluj, Romania) for $5 \mathrm{~min}$ [33]. Finally, the solid residue from the previous soymilk's preparation, called okara, was collected, freeze-dried (Martin Christ, Osterode am Harz, Germany) and stored at $4{ }^{\circ} \mathrm{C}$ in dark airtight jars.

For the formulation of the fermentation medium, the chickpea, quinoa, and buckwheat flours were mixed in equal proportions $(1: 1: 1, w / w)$ together with the amount of okara powder ranging between $0-16.9 \mathrm{~g} \%(w / w)$ according to the PBD or RSM runs and sterilized at $121^{\circ} \mathrm{C}$ for $15 \mathrm{~min}$ (Panasonic MLS-3871L, Bucharest, Romania). The distilled water was sterilized separately from the dry ingredients. The fermentation substrates were made by mixing the sterilized ingredients under aseptic conditions in a laminar-flow chamber (SafeFast, Faster, Cornaredo, Italy). The dough yield (DY) was calculated using Equation (1). Accordingly, softer (higher water content) sourdoughs have higher DY's [3,52]. The sourdough's ingredients and solid-state fermentation (SSF) conditions (LAB strain inoculum, fermentation time and temperature) were designed according to the statistical software (see Sections 3.1.1 and 3.1.2). After the fermentation, the resulting sourdough samples 
were freeze-dried and stored in sterile containers at $4{ }^{\circ} \mathrm{C}$. All the chemicals, reagents, and commercial culture media were purchased from Sigma-Aldrich (Steinheim, Germany).

$$
\text { Dough Yield }=\frac{\text { dough weight }(g)}{\text { flour weight }(g)} \times 100
$$

\subsection{Analysis of the Properties of Sourdoughs}

\subsubsection{Total Titratable Acidity}

For the determination of the total titratable acidity (TTA), $10 \mathrm{~g}$ of freeze-dried sourdough was mixed with $90 \mathrm{~mL}$ of distilled water. TTA was evaluated using an automatic titrator (TitroLine Easy, Schott Instruments, Mainz, Germany) and the results were expressed as the volume of $\mathrm{NaOH} 0.1 \mathrm{~N}(\mathrm{~mL})$ required to reach the $\mathrm{pH}$ value of $8.5[53,54]$.

\subsubsection{Antifungal Properties of Sourdoughs}

The PGA slants of Aspergillus niger, Aspergillus flavus and Penicillium spp. strains were used to collect the spores in a saline solution supplemented with $0.1 \%(v / v)$ Tween 80 (Sigma-Aldrich, Steinheim, Germany). Serial dilutions were made and the concentration of spores was established at $10^{4}$ spores $/ \mathrm{mL}$ using a Thoma counting chamber (Paul Marienfeld GmbH \& Co. KG, Lauda-Königshofen, Germany) $[55,56]$.

Petri dishes with $2 \%(w / v)$ of each freeze-dried sourdough sample were sterilized by UV for $30 \mathrm{~min}$ in a laminar-flow chamber [57]. Then, $20 \mathrm{~mL}$ of sterilized and melted (ca. $45-50^{\circ} \mathrm{C}$ ) PGA was poured into the dishes. After the homogenization of the mixture and solidification of the culture medium, a volume of $10 \mu \mathrm{L}$ of fungal spores suspension $\left(10^{4}\right.$ spores $\left./ \mathrm{mL}\right)$ was used for the inoculation on the surface of the culture medium [58]. The mycelium growth was measured after $96 \mathrm{~h}$ of incubation at $25^{\circ} \mathrm{C}$ under aerobiosis. The antifungal activity was expressed as inhibition ratio using Equation (2):

$$
I=\frac{A c-A t}{A c} \times 100
$$

where $I$ is the growth inhibition percentage, $A c$ is the diameter (in $\mathrm{mm}$ ) of the mycelial growth for the control sample (PGA without freeze-dried sourdough) and $A t$ is the diameter (in $\mathrm{mm}$ ) of the mycelial growth on the culture medium supplemented with $2 \%(w / v)$ of the tested sourdough sample from PBD or RSM [59].

\subsubsection{Antibacterial Properties of Sourdoughs}

The antibacterial activity of the prepared sourdoughs was determined following the experimental protocol described by Cotârleț et al. [60] with slight modifications. The overnight culture of Bacillus spp. strain was diluted in Nutrient Broth, to reach a target optical density of $0.05\left(\mathrm{OD}_{600 \mathrm{~nm}}\right)$ using a spectrophotometer [61]. Afterwards, the bacterial suspension $(10 \mu \mathrm{L})$ was used for the inoculation in the Petri dishes with sterilized and melted ( $c a .45-50{ }^{\circ} \mathrm{C}$ ) Nutrient Agar. After $24 \mathrm{~h}$ of incubation at $37^{\circ} \mathrm{C}$ under aerobiosis, the diameter (in $\mathrm{mm}$ ) of the bacterial colonies was measured, and the inhibition ratio was calculated using Equation (2), where $A c$ is the diameter (in $\mathrm{mm}$ ) of the bacterial growth for the control sample and $A t$ is the diameter (in $\mathrm{mm}$ ) of the bacterial growth on the culture medium supplemented with $2 \%(w / v)$ of the tested sourdough samples.

\subsection{Optimization of Sourdough Fermentation Parameters}

\subsubsection{Plackett-Burman Design (PBD)}

In the current study, a preliminary selection of the fermentation conditions (independent variables or factors) to produce sourdoughs was assessed through PBD. The mathematical modelling was produced using Equation (3):

$$
Y=\beta_{0}+\sum \beta_{i} X_{i}
$$


where $Y$ represents the response-i.e., the independent variables or observations, which were the TTA, expressed as $\mathrm{mL} \mathrm{NaOH} 0.1 \mathrm{~N}$, and antifungal and antibacterial activities, expressed as inhibition ratios: $\beta_{0}$ is the model intercept, $\beta_{i}$ is the linear coefficient; and $X_{i}$ is the level of the independent variables [62,63].

The analysis of the mathematical models was undertaken after collecting results from 12 independent runs taking into consideration all the factors and levels listed in Table 1.

Table 1. Plackett-Burman Design (PBD) independent variables (or factors).

\begin{tabular}{lcc}
\hline \multicolumn{1}{c}{$\begin{array}{c}\text { Codification of the Independent } \\
\text { Variables/Factors }\end{array}$} & $\begin{array}{c}\text { Minimum Value, } \\
\mathbf{- 1}\end{array}$ & $\begin{array}{c}\text { Maximum Value, } \\
\mathbf{+ 1}\end{array}$ \\
\hline A, Dough Yield (DY) & 250.00 & 700.00 \\
B, Inoculum of L. paracasei ssp. paracasei & 0.00 & 4.00 \\
MIUG BL 21 (\% v/w) & 0.00 & 4.00 \\
C, Inoculum of L. brevis MIUG BL 38 $(\%$ v/w) & 0.00 & 4.00 \\
D, Inoculum of L. parabuchneri MIUG BL 24 & & 4.00 \\
$(\%$ w w) & 0.00 & 10.00 \\
E, Inoculum of Leu. mesenteroides Ssp. & 0.00 & 45.00 \\
mesenteroides MIUG BL 40 $(\%$ v $w)$ & 25.00 & 96.00 \\
F, Okara $(\%$ w $w)$ & 24.00 & \\
G, Fermentation temperature $\left({ }^{\circ} \mathrm{C}\right)$ & & \\
H, Fermentation time $(\mathrm{h})$ &
\end{tabular}

\subsubsection{Response Surface Methodology (RSM)}

The factors that determined the significant predicable postbiotic effects on each of the studied responses were selected after PBD analysis. Moreover, it is important to highlight the significant interaction effects between the most important factors listed in Table 2.

Table 2. Response Surface Methodology (RSM) factors.

\begin{tabular}{|c|c|c|c|c|c|}
\hline \multirow{2}{*}{ Independent Variable/Factors } & \multirow{2}{*}{$\begin{array}{c}\text { Minimum Value, } \\
-1\end{array}$} & \multirow{2}{*}{$\begin{array}{c}\text { Central Value, } \\
0\end{array}$} & \multirow{2}{*}{$\begin{array}{c}\text { Maximum Value, } \\
+1\end{array}$} & \multicolumn{2}{|c|}{ Axial Points } \\
\hline & & & & $-\alpha$ & $+\alpha$ \\
\hline$A$, Dough Yield (DY) & 250.00 & 475.00 & 700.00 & -60.14 & 1010.14 \\
\hline $\begin{array}{l}\text { B, Inoculum of } L \text {. paracasei ssp. } \\
\text { paracasei MIUG BL } 21(\% v / w)\end{array}$ & 0.00 & 2.00 & 4.00 & -2.75 & 6.75 \\
\hline $\begin{array}{l}\text { C, Inoculum of L. parabuchneri MIUG } \\
\text { BL } 24(\% v / w)\end{array}$ & 0.00 & 2.00 & 4.00 & -2.75 & 6.75 \\
\hline$D$, Okara $(\%, w / w)$ & 0.00 & 5.00 & 10.00 & -6.89 & 16.89 \\
\hline$E$, Fermentation temperature $\left({ }^{\circ} \mathrm{C}\right)$ & 25.00 & 35.00 & 45.00 & 11.21 & 58.78 \\
\hline$F$, Fermentation time $(\mathrm{h})$ & 24.00 & 60.00 & 96.00 & -25.62 & 145.62 \\
\hline
\end{tabular}

The interaction effects were identified by a Central Composite Design (CCD) by RSM. With those 6 independent variables ( $A$ to $F$ ) and the corresponding levels previously described (Table 2), a two-level factorial design, half-fractional, CCD with 53 runs was employed, following the second order polynomial Equation (4):

$$
Y=\beta_{0}+\sum_{i=1}^{k} \beta_{i} X_{i}+\sum_{i=1}^{k} \beta_{i i} X_{i}^{2}+\sum_{i=1}^{k} \beta_{i j} X_{i} X_{j}
$$

where $Y$ represents the response-i.e., TTA expressed as $\mathrm{mL} \mathrm{NaOH} 0.1 \mathrm{~N}$, and antifungal and antibacterial activities, expressed as inhibition ratios; $\beta_{0}$ is the constant of the model; $\beta_{i}, \beta_{i i}$, and $\beta_{i j}$ are the coefficients for the linear, quadratic and interaction effects; $X_{i}$ and $X_{j}$ are independent variables, and $\mathrm{k}$ is the number of the studied factors [64]. 


\subsection{The Composition of Organic Acids, Flavonoids and Polyphenolic Compounds in Sourdoughs by RP-HPLC-DAD}

Organic acids, flavonoids and polyphenolic compounds were separated and partially identified by Reversed Phase (RP) High-Performance Liquid Chromatography system coupled with a Diode Array Detector (DAD). The organic acids in the unfermented (control) and the optimized fermented sourdough obtained by RSM were separated and partially identified using an HPLC system (Perkin Elmer, Flexar, Waltham, MA, USA) equipped with a solvent degasser, column oven, binary pump system and a DAD detector (Perkin Elmer, Flexar, Waltham, MA, USA). A Hamilton PRP X300 column $(250 \times 4.1 \mathrm{~mm}, 7 \mu \mathrm{m}$ particle size, Hamilton, Bonaduz, Switzerland) was used for the separation of the organic acids using a $20 \mathrm{mM} \mathrm{H}_{2} \mathrm{SO}_{4}$ acidified water as the mobile phase, under isocratic elution conditions, at $60^{\circ} \mathrm{C}$, and an optimal flow-rate of $1.5 \mathrm{~mL} / \mathrm{min}$. The total run time for the separation was $45 \mathrm{~min}$. The post-run time of $20 \mathrm{~min}$ was used to re-equilibrate the column. The detection of the organic acids was made in the ultra-violet- $C$ range at a wavelength of $210 \mathrm{~nm}(\lambda=210 \mathrm{~nm})$ after $15 \mathrm{~min}$ and integrated using the Chromera software, v. 3.3 [65].

The flavonoids and polyphenolic compounds from the optimized sourdough were separated by a Surveyor HPLC system (Finnigan Surveyor LC, Thermo Scientific, Waltham, MA, USA) equipped with autosampler, quaternary pump, photodiode-array (PDA) and UV-VIS detectors. A Synergi $4 \mathrm{u}$ Fusion-RP-80Å column $(150 \times 4.6 \mathrm{~mm}, 4 \mu \mathrm{m}$ particle size; Phenomenex, Torrance, CA, USA) was used for the separation following the methodology described by Montiel-Sánchez et al. (2020) [66] with minor modifications. Briefly, a binary elution system composed by $100 \%(v / v)$ methanol (solvent A) and $3 \%(v / v)$ formic acid (solvent B) was used. The separation was carried out at $30{ }^{\circ} \mathrm{C}$ for a total run time of $55 \mathrm{~min}$ using the following elution pattern with a linear gradient for the separation and further identification of these above-mentioned bioactive compounds: starting from $91 \%$ B within 0-20 min; decreasing at 65\% B within $20 \mathrm{~min}$ (from 20 to $40 \mathrm{~min}$ ); and increasing at $91 \%$ B (from 40-55 min). The post-run time of $20 \mathrm{~min}$ was used to re-equilibrate the column. The separation was made at an optimal flow-rate of $1 \mathrm{~mL} / \mathrm{min}$. The compounds of interest were simultaneously detected in the UV-B and UV-A ranges at the wavelengths of 280 and $320 \mathrm{~nm}$, respectively. The detection and integration were made resorting to the Xcalibur software, v. 2.1.

Prior to the HPLC separations, $2 \mathrm{~g}$ of freeze-dried sourdough samples, respectively, the sample fermented under optimized conditions and the unfermented sample (control) were resuspended in $5 \mathrm{~mL}$ of $20 \mathrm{mM} \mathrm{H}_{2} \mathrm{SO}_{4}$ acidified water or $5 \mathrm{~mL} 70 \%(v / v)$ methanol for the organic acids, flavonoids and polyphenols separation, respectively. The mixtures were dissolved by sonication for $45 \mathrm{~min}$, using an ultrasonic bath (MRC, Holon, Israel). Before the HPLC injection, the supernatants of the sample mixtures were collected after centrifugation at $6000 \mathrm{rpm}$ and $4{ }^{\circ} \mathrm{C}$ for $10 \mathrm{~min}$ (Hettich Universal 320R, Tuttlingen, Germany) and filtrated through $0.22 \mu \mathrm{m}$ syringe filters (Merck, Darmstadt, Germany) [67].

The organic acids, flavonoids and polyphenols of the analyzed samples were identified after their separation by comparing the retention times to external standards. All external standards were purchased from Sigma-Aldrich (Steinheim, Germany).

\subsection{Statistical Analysis}

Plackett-Burman Design (PBD) was used to determine the most important variables for the functional properties of the sourdough. As previously mentioned, 8 independent variables were evaluated: $A$-dough yield; $B$-inoculum of $L$. paracasei ssp. paracasei MIUG BL 21 strain $(\% v / w)$; C-inoculum of L. brevis MIUG BL 38 strain $(\% v / w) ; D$-inoculum of L. parabuchneri MIUG BL 24 strain ( $\% v / w)$; E-inoculum of Leu. mesenteroides ssp. mesenteroides MIUG BL 40 strain $(\% v / w)$; F-okara ( $\% w / w)$; G-fermentation temperature $\left({ }^{\circ} \mathrm{C}\right)$; and $\mathrm{H}$-fermentation time (h). The effect of the above-mentioned factors was tested on the following responses: TTA $(\mathrm{mL} \mathrm{NaOH} 0.1 \mathrm{~N})$; antifungal activity against $A s-$ pergillus niger, A. flavus, and Penicillium spp. and antibacterial activity against Bacillus spp. $(I, \%$, Equation (2)). Among all those factors, 6 of them had a significant impact on the 
studied responses, namely: $A$-dough yield (Equation (1)); $B$-inoculum of L. paracasei ssp. paracasei MIUG BL 21 strain ( $\% v / w)$; C-inoculum of L. parabuchneri MIUG BL 24 strain $(\%$ $v / w)$; $D$-okara $(\% w / w)$; E-fermentation temperature $\left({ }^{\circ} \mathrm{C}\right)$; and $F$-fermentation time (h). These six factors were further included in a half-fractional Central Composite Design (CCD) using the RSM analysis with 53 runs ( 32 cube points, 9 center points in cube and 12 axial points). The negative values for the axial points $(-\alpha)$ were considered 0 . Minitab 19 (v. 1.1, LLC, College, PA, USA) was used for the design of experiments and one-way analysis of variance (ANOVA) was evaluated considering a confidence interval of $95 \%$. The fitting of the models was evaluated based on the regression coefficient $\left(R^{2}\right)$, lack of fit, and $p$-value $<0.05$. Two parallel experimental runs were performed, and the reported results are the average values of duplicate measurements for each analysis.

\section{Results and Discussion}

\subsection{Sourdough Fermentation Process Optimization}

3.1.1. Selection of the Most Important Fermentation Parameters by Plackett-Burman Design (PBD)

Following the combinations of factors at different levels (Table 1) obtained by PBD, the variations between the experimental results for the studied responses were observed, as it is shown in Table 3. The acidification capacity expressed as TTA varied between 5.90 to $38.90 \mathrm{~mL} \mathrm{NaOH} 0.1 \mathrm{~N}$. As expected, the lowest TTA value was determined for the uninoculated dough incubated for $24 \mathrm{~h}$ at $25^{\circ} \mathrm{C}$. The most acidified sample was obtained with a mixed inoculum containing the LAB strains of L. paracasei ssp. paracasei MIUG BL 21, L. brevis MIUG BL 38 and Leu. mesenteroides ssp. mesenteroides MIUG BL 40 after the fermentation of a medium containing $10 \%(w / w)$ okara powder. For some samples, a mixed inoculum did not determine a high level of TTA, most likely due to the competitive and/or antagonistic effects between the studied LAB strains. Similar results were reported by Siepmann et al. [68], who reported differences between the TTA values when various strains of Lactobacillus spp. and Pediococcus pentosaceus were co-inoculated as starter cultures for the wheat-based sourdoughs. For some LAB strains, a fermentation temperature of $35^{\circ} \mathrm{C}$ caused TTA values below $4.0 \mathrm{~mL} \mathrm{NaOH} 0.1 \mathrm{~N}$, whereas a mixed inoculum composed by the four studied LAB strains caused a significant increase in TTA values to $13.0 \mathrm{~mL}$ after the sourdough's fermentation at $28^{\circ} \mathrm{C}$. The reported results underline the importance of the fermentation temperatures on the microbial and enzymatic activities of pseudocereal and legume flours.

Table 3. Experimental results of the total titratable acidity (TTA) and inhibition ratio (I, \%, defined by the Equation (2)) obtained by Plackett-Burman Design (PBD) analysis. The meaning of the factors $A$ to $H$ is given in Table 1 .

\begin{tabular}{|c|c|c|c|c|c|c|c|c|c|c|c|c|c|}
\hline \multirow[b]{2}{*}{ Run } & \multicolumn{8}{|c|}{ Factors } & \multicolumn{5}{|c|}{ Responses } \\
\hline & $A$ & B & $C$ & $D$ & $E$ & $F$ & $G$ & $H$ & $\begin{array}{c}\text { TTA, } \\
\text { mL NaOH } \\
0.1 \mathrm{~N}\end{array}$ & $\begin{array}{c}\mathrm{I}, \% \\
\text { A. niger } 1\end{array}$ & $\begin{array}{c}\text { I, } \% \\
\text { A. flavus }\end{array}$ & $\begin{array}{c}\text { I, \% } \\
\text { Penicillium } \\
\text { spp. } 1\end{array}$ & $\begin{array}{c}\text { I, \% } \\
\text { Bacillus } \\
\text { spp. }{ }^{1}\end{array}$ \\
\hline 1 & 250.00 & 4.00 & 4.00 & 0.00 & 4.00 & 0.00 & 25.00 & 24.00 & 11.23 & 21.27 & 56.36 & 6.90 & 2.23 \\
\hline 2 & 700.00 & 0.00 & 0.00 & 0.00 & 4.00 & 10.00 & 45.00 & 24.00 & 11.00 & -0.81 & 43.18 & -1.55 & -9.48 \\
\hline 3 & 700.00 & 0.00 & 4.00 & 0.00 & 0.00 & 0.00 & 45.00 & 96.00 & 10.67 & 41.64 & 45.45 & 8.90 & -34.50 \\
\hline 4 & 250.00 & 4.00 & 0.00 & 0.00 & 0.00 & 10.00 & 45.00 & 96.00 & 13.73 & 31.26 & 57.73 & 29.83 & -36.07 \\
\hline 5 & 700.00 & 4.00 & 0.00 & 4.00 & 4.00 & 0.00 & 45.00 & 24.00 & 14.77 & -8.88 & 51.82 & 16.21 & 2.69 \\
\hline 6 & 250.00 & 4.00 & 4.00 & 4.00 & 0.00 & 10.00 & 45.00 & 24.00 & 10.23 & -6.43 & 51.36 & 55.00 & -16.42 \\
\hline 7 & 700.00 & 4.00 & 0.00 & 4.00 & 0.00 & 0.00 & 25.00 & 96.00 & 27.10 & -7.97 & 51.82 & 21.55 & 16.60 \\
\hline 8 & 700.00 & 0.00 & 4.00 & 4.00 & 0.00 & 10.00 & 25.00 & 24.00 & 27.87 & -32.96 & 29.09 & -2.41 & -11.59 \\
\hline 9 & 250.00 & 0.00 & 4.00 & 4.00 & 4.00 & 0.00 & 45.00 & 96.00 & 11.60 & 10.03 & 50.00 & 23.45 & -5.46 \\
\hline 10 & 250.00 & 0.00 & 0.00 & 4.00 & 4.00 & 10.00 & 25.00 & 96.00 & 28.77 & 10.76 & 43.18 & 24.83 & 25.55 \\
\hline 11 & 250.00 & 0.00 & 0.00 & 0.00 & 0.00 & 0.00 & 25.00 & 24.00 & 5.90 & 13.55 & 15.00 & -21.03 & 25.27 \\
\hline 12 & 700.00 & 4.00 & 4.00 & 0.00 & 4.00 & 10.00 & 25.00 & 96.00 & 38.90 & -6.72 & 50.91 & 26.90 & 65.22 \\
\hline
\end{tabular}

${ }^{1}$ Negative values resulting from the calculation of the inhibition ratio. These values have statistical relevance for the mathematical modelling. 
Another key-variable for the TTA response was represented by the fermentation time (Table 3). Our results suggested that an extension of the incubation time up to $96 \mathrm{~h}$ could result in higher levels of TTA, depending on the LAB strains used as inoculum. In a work from Comasio et al. [54], the TTA values above $10.0 \mathrm{~mL} \mathrm{NaOH} \mathrm{0.1N} \mathrm{were} \mathrm{obtained} \mathrm{with}$ some selected Lactobacillus spp. strains, after $72 \mathrm{~h}$ of fermentation at $30{ }^{\circ} \mathrm{C}$ of a wheat-based sourdough. Furthermore, the amount and type of flours and other ingredients used in the sourdough recipes for bakery products, as well as the number and type of LAB strains employed during the fermentation and the consistency of the sourdoughs (i.e., the DY) may cause significant changes upon the acidification potential. Accordingly, different types of cereal flours have different buffer capacities, and different LAB strains in the same or different dough mixtures lead to different types of organic acids and respective yields of production [53,69-71].

The high antimicrobial activities of the fermented products (Table 3) were determined against Aspergillus niger and Aspergillus flavus as indicator fungal strains, after $96 \mathrm{~h}$ of incubation at $45^{\circ} \mathrm{C}$ and after $24 \mathrm{~h}$ of fermentation at $25^{\circ} \mathrm{C}$, respectively. The data showed in Table 3 indicate that some LAB strains used for the fermentation of sourdough were not able to inhibit the fungal or bacterial growth, namely of Penicillium spp. or Bacillus spp. strains, respectively. However, the antimicrobial compounds produced during the SSF process of the gluten-free flours formulated media by LAB strains used in this study possessed different inhibitory potentials against the indicator strains of molds and bacterium (Table 3).

According to the ANOVA results displayed in Tables S1-S5, the type of LAB strains used as the inoculum, the addition of okara in the fermentation medium, as well as the fermentation temperature and time led to distinct impacts on the analyzed responses. Particularly, the factors $A$ (dough yield), D (inoculum of L. parabuchneri MIUG BL 24 strain, $\% v / w), F($ okara, $\% w / w), G$ (fermentation temperature, ${ }^{\circ} \mathrm{C}$ ) and $H$ (fermentation time, $\mathrm{h}$ ) had significant impacts $(p<0.05)$ on the TTA. The mathematical model generated on the TTA was also significant $(p=0.014)$ with a regression coefficient $\left(\mathrm{R}^{2}\right)$ of 0.9827 (Table S1).

The growth of the fungal indicator strains used in this study revealed different behaviors, depending on the strain. Aspergillus niger's growth was significantly inhibited $(p<0.05)$ by the variation of the factors $A$ (dough yield), $D$ (L. parabuchneri MIUG BL 24 strain inoculum, $\% v / w$ ), and $H$ (fermentation time, h) involved in the sourdoughs' fermentation processes, as showed in Table S2.

Moreover, the analysis of variance (ANOVA) from Tables S3 and S4 unfolded the influence of the factor $B$ (L. paracasei ssp. paracasei MIUG BL 21 strain inoculum, \% $v / w$ ) on the inhibitory potential of the sourdoughs against Aspergillus flavus and Penicillium spp. strains.

The temperature (factor $G$ ) through the SSF greatly influenced the sourdoughs' antifungal activity against Aspergillus flavus. In contrast, the same factor $G$ had no significant effect against Penicillium spp. Moreover, the L. parabuchneri MIUG BL 24 strain inoculum (factor $D$ ), along with the fermentation time (factor $H$ ), contributed significantly to attain a sourdough with an inhibitory effect against Penicillium spp. The antibacterial activity of the sourdoughs against Bacillus spp. was strongly influenced $(p<0.05)$ by the factor $G$ (fermentation temperature, ${ }^{\circ} \mathrm{C}$ ). This statistical model was significant $(p=0.026)$ but its regression coefficient was only $66.66 \%\left(\mathrm{R}^{2}=0.6666\right)$ (Table S5).

Taking into consideration that the fermentation temperature had a significant impact on the antibacterial activity of the sourdoughs against the Bacillus spp. strain, and simultaneously proved to be an important factor regarding other generated models (viz., TTA and growth inhibition of Aspergillus flavus), the antibacterial activity of the sourdoughs was, therefore, included in the further studies by RSM.

Overall, by analyzing all the models with the responses of interest using the PBD, factor $E$ (Leu. mesenteroides ssp. mesenteroides MIUG BL 40 inoculum) previously identified as an important exopolysaccharide producing strain [45], it has not been statistically significant for the responses studied in this work. Thus, six factors were proved to be significant on the sourdough properties, chiefly dough yield, L. paracasei ssp. paracasei MIUG BL 21 and 
L. parabuchneri MIUG BL 24 strains' inoculum concentration, okara amount, fermentation temperature and time-thus being selected for the further optimization studies by RSM.

3.1.2. Optimization of Gluten-Free Sourdough's Solid-State Fermentation (SSF) by Response Surface Methodology (RSM)

The factors $A$, dough yield; $B, L$. paracasei ssp. paracasei MIUG BL 21 strain inoculum (\% v/w); C, L. parabuchneri MIUG BL 24 strain inoculum (\% v/w); D, okara (\% w/w); $E$, fermentation temperature $\left({ }^{\circ} \mathrm{C}\right)$; and $F$, fermentation time $(\mathrm{h})$ (Table 2) previously selected (see Section 3.1.1) were used for the RSM analysis, the results for each response being listed in Table 4.

\section{(1) Acidification Capacity (TTA)}

Regarding the acidification capacity of the studied LAB strains in the sourdoughs, it can be observed from Table 4 that the highest values for the TTA were achieved at $35{ }^{\circ} \mathrm{C}$ after $60 \mathrm{~h}$ of fermentation with different inoculum types and concentrations. Analyzing the results (Table 4) in the sourdough samples with the lowest consistency (i.e., highest DY of 700), an increase in TTA was observed with increasing temperature and okara concentration, when the sourdough was inoculated uniquely with the L. parabuchneri MIUG BL 24 strain. Moreover, the L. paracasei ssp. paracasei MIUG BL 21 strain produced higher amounts of organic acids when the fermentation time ranged between $60 \mathrm{~h}$ and $96 \mathrm{~h}$. A synergistic effect on the TTA values was detected when the studied lactobacilli strains were used together and, simultaneously, when the fermentation medium was supplemented with $10 \%(w / w)$ okara powder and $96 \mathrm{~h}$ of fermentation was applied.

The used indicator molds and the bacterial strains (i.e., Aspergillus niger, Aspergillus flavus, Penicillium spp. and Bacillus spp., respectively), were inhibited in different manners by the obtained samples of the sourdough formulated based on the optimization design and principles. The negative inhibition ratios were calculated. Thus, these values helped for a better discrimination of the results towards an optimized sourdough formulation.

The most acidified sourdough sample-obtained with the co-culture of both selected lactobacilli strains determined a total inhibition of Aspergillus niger, Penicillium spp. and Bacillus spp., whereas only a growth inhibition ratio of $75.9 \%$ was attained for Aspergillus flavus. Another promising result was found when the sourdough was fermented with a co-culture of $2 \%(v / w)$ of each L. paracasei ssp. paracasei and L. parabuchneri strain's inoculum at $35{ }^{\circ} \mathrm{C}$ for $60 \mathrm{~h}$. The combination of these parameters along with the use of $16.9 \%(w / w)$ of okara powder provided a sourdough with the capacity to fully inhibit the growth of Aspergillus flavus, Penicillium spp. and Bacillus spp.

Each mold and spoilage bacteria strains used as the indicators in this study were fully inhibited by specific sourdoughs prepared under certain combinations of factors obtained by the RSM model. In fact, in this work it was essential to identify the most important fermentation factors, and their most favorable amounts and combinations in order to maximize the sourdough's overall antimicrobial properties and its content of the studied compounds with potential bioactive and/or technological functionalities, viz. organic acids, flavonoids and polyphenolic compounds [3,72,73]. 


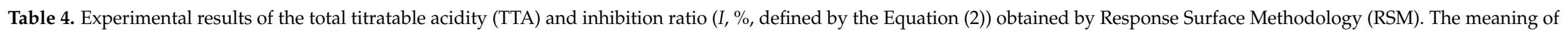
the selected factors $A$ to $F$ is given in Table 2.

\begin{tabular}{|c|c|c|c|c|c|c|c|c|c|c|c|}
\hline \multirow[b]{2}{*}{ Run } & \multicolumn{6}{|c|}{ Factors } & \multicolumn{5}{|c|}{ Responses } \\
\hline & $A$ & $B$ & $C$ & $D$ & $E$ & $F$ & $\begin{array}{c}\text { TTA, mL NaOH } \\
0.1 \mathrm{~N}\end{array}$ & $\begin{array}{c}\text { Antifungal Activity } \\
\text { against } \\
\text { A. niger } \mathrm{I}, \%^{1}\end{array}$ & $\begin{array}{c}\text { Antifungal Activity } \\
\text { against A. flavus I, } \\
\%_{1}^{1}\end{array}$ & $\begin{array}{l}\text { Antifungal Activity } \\
\text { against Penicillium } \\
\text { spp. I, } \%{ }^{1}\end{array}$ & $\begin{array}{c}\text { Antibacterial } \\
\text { Activity against } \\
\text { Bacillus spp. I, } \% 1\end{array}$ \\
\hline 1 & 250.00 & 4.00 & 0.00 & 0.00 & 45.00 & 24.00 & 9.30 & -35.00 & 24.09 & 42.50 & 18.00 \\
\hline 2 & 250.00 & 0.00 & 4.00 & 0.00 & 45.00 & 24.00 & 10.50 & -57.00 & 4.09 & 27.50 & 30.00 \\
\hline 3 & 250.00 & 4.00 & 4.00 & 0.00 & 45.00 & 96.00 & 20.00 & -34.38 & 11.14 & 28.75 & 27.50 \\
\hline 4 & 475.00 & 2.00 & 2.00 & 5.00 & 35.00 & 145.62 & 22.00 & 15.00 & 56.82 & 67.50 & 78.00 \\
\hline 5 & 475.00 & 2.00 & 2.00 & 5.00 & 35.00 & 60.00 & 26.00 & 40.00 & 81.82 & 100.00 & 100.00 \\
\hline 7 & 250.00 & 4.00 & 4.00 & 10.00 & 45.00 & 24.00 & 23.00 & 40.00 & 61.82 & 62.50 & 42.00 \\
\hline 8 & 250.00 & 4.00 & 4.00 & 10.00 & 25.00 & 96.00 & 24.00 & 70.00 & 66.36 & 62.50 & 100.00 \\
\hline 9 & 475.00 & 2.00 & 2.00 & 5.00 & 35.00 & 60.00 & 24.00 & 40.00 & 63.18 & 66.25 & 20.00 \\
\hline 10 & -60.14 & 2.00 & 2.00 & 5.00 & 35.00 & 60.00 & 0.00 & 0.00 & 0.00 & 0.00 & 0.00 \\
\hline 11 & 700.00 & 0.00 & 0.00 & 0.00 & 25.00 & 96.00 & 2.00 & -14.00 & 43.64 & 2.00 & -55.00 \\
\hline 12 & 700.00 & 0.00 & 4.00 & 0.00 & 25.00 & 24.00 & 9.00 & 32.00 & 35.00 & 20.00 & 36.00 \\
\hline 13 & 475.00 & 2.00 & 2.00 & 16.89 & 35.00 & 60.00 & 28.05 & 60.00 & 100.00 & 100.00 & 100.00 \\
\hline 14 & 700.00 & 0.00 & 0.00 & 10.00 & 25.00 & 24.00 & 9.00 & -36.00 & 11.82 & -32.79 & -61.00 \\
\hline 15 & 700.00 & 4.00 & 4.00 & 10.00 & 45.00 & 96.00 & 29.00 & 0.00 & 31.06 & 50.00 & 63.00 \\
\hline 17 & 700.00 & 4.00 & 4.00 & 0.00 & 25.00 & 96.00 & 22.00 & 55.00 & 49.09 & 41.25 & 100.00 \\
\hline 18 & 250.00 & 0.00 & 0.00 & 10.00 & 25.00 & 96.00 & 8.00 & 30.00 & 20.91 & -28.45 & -7.00 \\
\hline 19 & 700.00 & 4.00 & 4.00 & 0.00 & 45.00 & 24.00 & 20.00 & 8.00 & 50.00 & 68.75 & 54.17 \\
\hline 20 & 475.00 & 2.00 & 2.00 & 5.00 & 35.00 & 60.00 & 24.00 & 56.00 & 60.45 & 65.00 & 83.33 \\
\hline 21 & 475.00 & 2.00 & 2.00 & -6.89 & 35.00 & 60.00 & 23.00 & 40.00 & 62.27 & 77.50 & 95.83 \\
\hline 22 & 250.00 & 0.00 & 0.00 & 10.00 & 45.00 & 24.00 & 10.00 & -35.00 & -9.09 & -23.32 & -24.17 \\
\hline 23 & 700.00 & 4.00 & 0.00 & 0.00 & 45.00 & 96.00 & 14.00 & 18.50 & 47.73 & 56.25 & 55.00 \\
\hline 24 & 475.00 & 2.00 & 2.00 & 5.00 & 35.00 & 60.00 & 15.00 & 2.00 & 100.00 & 38.75 & 72.00 \\
\hline 25 & 250.00 & 4.00 & 0.00 & 10.00 & 45.00 & 96.00 & 9.00 & -9.00 & -18.64 & 27.50 & 14.00 \\
\hline 26 & 1010.14 & 2.00 & 2.00 & 5.00 & 35.00 & 60.00 & 15.00 & 15.00 & 46.82 & 38.92 & 100.00 \\
\hline 27 & 250.00 & 0.00 & 4.00 & 10.00 & 45.00 & 96.00 & 20.00 & -30.00 & 0.00 & 33.75 & 83.00 \\
\hline 28 & 250.00 & 0.00 & 4.00 & 0.00 & 25.00 & 96.00 & 19.00 & 58.00 & 59.55 & 70.00 & 100.00 \\
\hline 29 & 475.00 & 2.00 & 2.00 & 5.00 & 35.00 & 60.00 & 26.00 & 43.00 & 50.00 & 68.75 & 90.00 \\
\hline 30 & 250.00 & 4.00 & 4.00 & 0.00 & 25.00 & 24.00 & 9.00 & 25.00 & 32.73 & 38.75 & 38.33 \\
\hline 31 & 700.00 & 0.00 & 4.00 & 10.00 & 45.00 & 24.00 & 21.00 & 20.00 & 45.15 & 41.25 & 47.50 \\
\hline
\end{tabular}


Table 4. Cont.

\begin{tabular}{|c|c|c|c|c|c|c|c|c|c|c|c|}
\hline \multirow[b]{2}{*}{ Run } & \multicolumn{6}{|c|}{ Factors } & \multicolumn{5}{|c|}{ Responses } \\
\hline & $A$ & $B$ & $C$ & $D$ & $E$ & $F$ & $\begin{array}{c}\text { TTA, mL NaOH } \\
0.1 \mathrm{~N}\end{array}$ & $\begin{array}{c}\text { Antifungal Activity } \\
\text { against } \\
\text { A. niger I, } \%{ }^{1}\end{array}$ & $\begin{array}{c}\text { Antifungal Activity } \\
\text { against } A \text {. flavus } \mathrm{I}, \\
\%_{1}^{1}\end{array}$ & $\begin{array}{c}\text { Antifungal Activity } \\
\text { against Penicillium } \\
\text { spp. I, } \%^{1}\end{array}$ & $\begin{array}{c}\text { Antibacterial } \\
\text { Activity against } \\
\text { Bacillus spp. I, } \% 1\end{array}$ \\
\hline 32 & 475.00 & 2.00 & 2.00 & 5.00 & 35.00 & 60.00 & 24.00 & 45.00 & 55.91 & 61.25 & 81.67 \\
\hline 33 & 700.00 & 4.00 & 0.00 & 10.00 & 25.00 & 96.00 & 25.00 & 20.00 & 58.64 & 61.25 & 100.00 \\
\hline 34 & 250.00 & 4.00 & 0.00 & 10.00 & 25.00 & 24.00 & 10.00 & 10.00 & 38.18 & 33.75 & -10.00 \\
\hline 35 & 475.00 & 2.00 & 2.00 & 5.00 & 35.00 & -25.62 & 9.00 & 3.00 & 37.73 & 41.25 & 60.00 \\
\hline 36 & 250.00 & 4.00 & 0.00 & 0.00 & 25.00 & 96.00 & 19.00 & 75.00 & 76.82 & 70.00 & 100.00 \\
\hline 37 & 250.00 & 0.00 & 0.00 & 0.00 & 45.00 & 96.00 & 7.00 & -20.00 & 31.82 & -21.38 & -16.00 \\
\hline 38 & 475.00 & 2.00 & 2.75 & 5.00 & 35.00 & 60.00 & 15.00 & 36.00 & 56.82 & 52.62 & 63.33 \\
\hline 39 & 475.00 & 2.00 & 2.00 & 5.00 & 35.00 & 60.00 & 25.00 & 88.00 & 62.73 & 67.50 & 100.00 \\
\hline 40 & 475.00 & 2.75 & 2.00 & 5.00 & 35.00 & 60.00 & 23.00 & 40.00 & 62.27 & 35.75 & 90.00 \\
\hline 41 & 250.00 & 0.00 & 4.00 & 10.00 & 25.00 & 24.00 & 10.00 & -2.00 & 27.27 & 43.75 & 50.83 \\
\hline 42 & 475.00 & 6.75 & 2.00 & 5.00 & 35.00 & 60.00 & 27.00 & 44.00 & 69.55 & 87.50 & 100.00 \\
\hline 43 & 700.00 & 0.00 & 4.00 & 0.00 & 45.00 & 96.00 & 20.00 & 20.00 & 40.91 & 40.00 & 54.17 \\
\hline 44 & 475.00 & 2.00 & 2.00 & 5.00 & 35.00 & 60.00 & 25.00 & 50.00 & 50.45 & 81.25 & 91.67 \\
\hline 45 & 700.00 & 4.00 & 0.00 & 10.00 & 45.00 & 24.00 & 10.00 & -36.00 & 11.36 & 31.25 & 59.17 \\
\hline 46 & 700.00 & 0.00 & 0.00 & 0.00 & 45.00 & 24.00 & 7.00 & -11.00 & -6.82 & -21.56 & -40.00 \\
\hline 48 & 250.00 & 0.00 & 0.00 & 0.00 & 25.00 & 24.00 & 7.00 & -21.00 & 15.91 & -35.93 & -17.00 \\
\hline 49 & 475.00 & 2.00 & 2.00 & 5.00 & 58.78 & 60.00 & 11.00 & 2.50 & 0.00 & 36.25 & 58.00 \\
\hline 50 & 475.00 & 2.00 & 2.00 & 5.00 & 35.00 & 60.00 & 25.00 & 60.00 & 61.82 & 67.50 & 100.00 \\
\hline 51 & 475.00 & 2.00 & 2.00 & 5.00 & 11.21 & 60.00 & 5.00 & 7.00 & 38.64 & 43.75 & 60.00 \\
\hline 52 & 700.00 & 0.00 & 0.00 & 10.00 & 45.00 & 96.00 & 10.00 & -35.00 & -11.36 & -31.67 & -60.00 \\
\hline 53 & 700.00 & 4.00 & 4.00 & 10.00 & 25.00 & 24.00 & 12.00 & 32.00 & 25.00 & 25.00 & 34.00 \\
\hline
\end{tabular}

${ }^{1}$ Negative values resulting from the calculation of the inhibition ratio. These values have statistical relevance for the mathematical modelling. 
Regarding the TTA, the impact of each independent variable on its value can be determined by the mathematical model expressed in Equation (5) and obtained via RSM:

$$
\begin{gathered}
\text { TTA }=-46.500+0.051 A+1.270 B-1.690 C-0.050 D+2.338 E+0.305 F-0.032 B^{2}-0.143 C^{2}- \\
0.002 D^{2}-0.031 E^{2}-0.001 F^{2}+0.001 A B+0.001 A C+0.002 A E-0.170 B C-0.040 B D-0.021 B E+ \\
0.014 B F+0.059 C D+0.074 C E+0.019 C F-0.001 D E-0.004 E F
\end{gathered}
$$

The significant interaction effects on TTA $(p<0.05)$ were identified, on the one hand, between variables $C$ and $E$ (L. parabuchneri MIUG BL 24 strain's inoculum $(\% v / w)$, and the fermentation temperature, ${ }^{\circ} \mathrm{C}$ ), as it is shown in Table $\mathrm{S} 6$ for the ANOVA results. The TTA values increased along with the increment of the inoculum volume of L. parabuchneri MIUG BL 24 strain. The maximum TTA values could be reached when the inoculum volumes above $6.74(\% v / w)$ of L. parabuchneri MIUG BL 24 strain were used simultaneously with temperatures ranging between 35.90 and $47.92{ }^{\circ} \mathrm{C}$ (Figure 1a,b). On the other hand, a significant interaction effect was identified between variables $E$ and $F$ (fermentation temperature, ${ }^{\circ} \mathrm{C}$ and fermentation time, $\mathrm{h}$, respectively) for the TTA. A prolonged fermentation time determined a high level of TTA, whereas a minimized response was observed at a fermentation temperature below $21^{\circ} \mathrm{C}$ or above $45^{\circ} \mathrm{C}$ (Figure 1c,d).

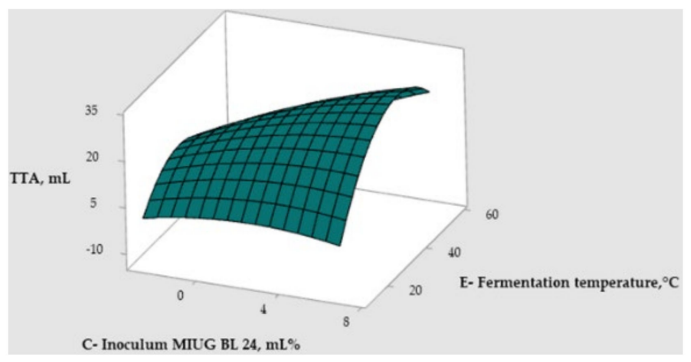

(a)

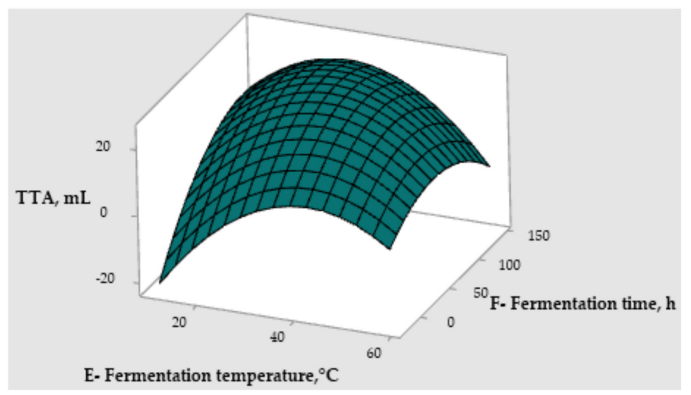

(c)

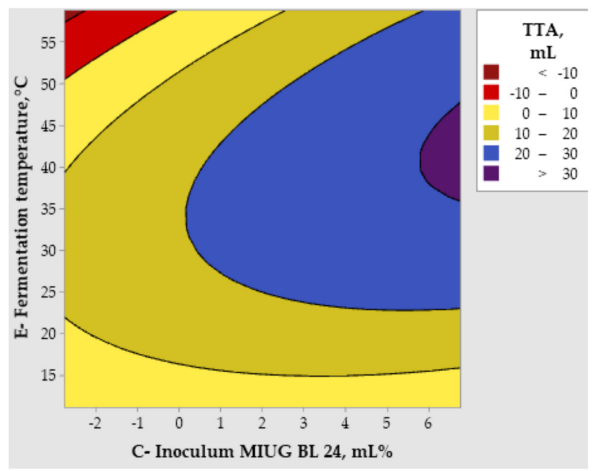

(b)

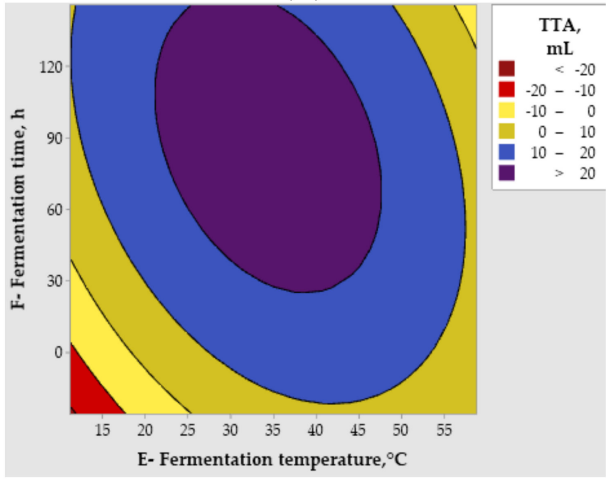

(d)

Figure 1. Surface (left) and contour (right) plots for the two-way interactions between the significant

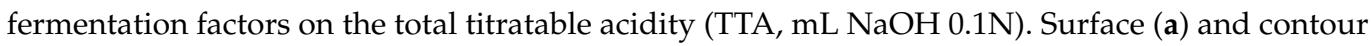
(b) plots for the interaction between the factors $C$ and $E$, and (c) surface and (d) contour plots for the interaction between the factors $E$ and $F$. The mean of the factors $A$ to $F$ is given in Table 2.

As displayed in Table S6 the regression coefficient $\left(R^{2}\right)$ for the mathematical model of TTA was $88 \%$, showing that the model fits very well with the experimental values and is in agreement with the P-value obtained for the lack of fit $(p>0.05)$.

(2) Inhibitory Effects

Regarding the microbial growth inhibition studies, the Aspergillus niger strain's growth was significantly influenced $(p<0.05)$ only by the linear effect of the sourdough's fermenta- 
tion variables $B, C$ and $E$ (Table 2) by their quadratic effects $A^{2}, E^{2}, F^{2}$, respectively. Table S6 highlighted the good fit of the above-mentioned model to the experimental results, proven by the P-value for the lack of fit (0.25) and, concurrently, by the regression coefficient higher than $70 \%\left(R^{2}=0.72\right)$. The regression Equation (6) obtained for the inhibition against Aspergillus niger strain by RSM was as follows:

$$
\begin{gathered}
I, \%=-174.000+0.127 A+20.300 B+5.200 C+1.350 D+5.710 E+2.333 F-1.012 B^{2}+0.137 C^{2}- \\
0.105 D^{2}-0.106 E^{2}-0.008 F^{2}-0.006 A B+0.012 A C-0.007 A D+0.004 A E-0.590 B C+0.140 B D- \\
0.242 B E-0.006 B F+0.475 C D-0.097 C E-0.062 C F+0.079 D E-0.020 D F-0.019 E F
\end{gathered}
$$

Furthermore, the mathematical model corresponding to the inhibitory effect of the formulated sourdoughs against Aspergillus flavus strain was expressed by the Equation (7):

$$
\begin{gathered}
I, \%=-143.200+0.143 A+10.900 B-2.640 C+0.930 D+6.830 E+1.628 F-0.592 B^{2}-0.572 C^{2}+ \\
0.013 D^{2}-0.106 E^{2}-0.004 F^{2}-0.004 A B+0.004 A C+0.001 A E-1.131 B C+0.009 B D+0.028 B E- \\
\quad 0.044 B F+0.700 C D+0.186 C E-0.030 C F-0.034 D E-0.026 D F-0.023 E F
\end{gathered}
$$

A significant interaction effect on the antifungal activity of the formulated sourdoughs against Aspergillus flavus strain was perceived between the factors' fermentation time and temperature. It can be concluded, from the surface (Figure 2a) and contour (Figure $2 b$ ) plots, that a fermentation temperature higher than $44{ }^{\circ} \mathrm{C}$ would minimize the antifungal effects of the gluten-free fermented products against Aspergillus flavus strain, which is obviously related to the effect of the temperature on the LAB's activity and growth-rates.

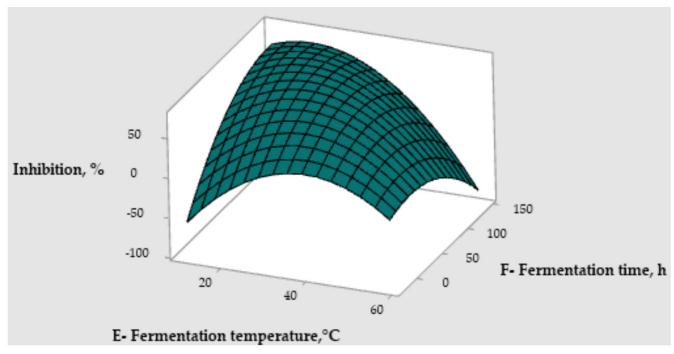

(a)

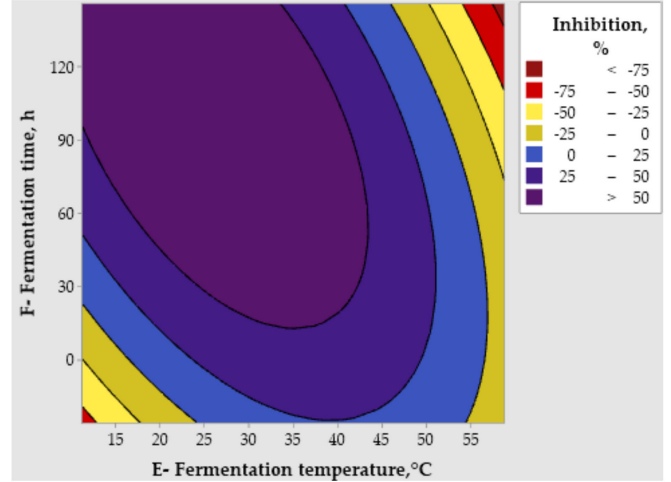

(b)

Figure 2. Surface (a) and contour (b) plots for the two-way interactions between the significant fermentation variables $E$ and $F$ on the antifungal activity (inhibition ratio, \%) against Aspergillus flavus. The mean of the factors $A$ to $F$ is given in Table 2.

Regarding the inhibitory effect of the formulated sourdoughs against Penicillium spp. and Bacillus spp. indicator strains, the inhibition effects induced by varying the factors $B$ and $C$ (Table 2) in their 2-way interaction were shown in Figures 3 and 4 . For the antifungal activity against Penicillium spp. indicator strain the calculated regression Equation (8) was:

$$
\begin{gathered}
I, \%=-193.200+0.200 A+20.250 B+16.750 C+0.520 D+6.400 E+1.517 F-1.261 B^{2}-0.612 C^{2}- \\
0.010 D^{2}-0.089 E^{2}-0.005 F^{2}-0.005 A C+0.001 A D+0.001 A E-3.979 B C-0.029 B D+0.069 B E- \\
0.020 B F+0.416 C D+0.073 C E-0.020 C F-0.002 D E-0.010 D F-0.021 E F
\end{gathered}
$$

Consequently, a full inhibition against Penicillium spp. indicator strain was determined by the sourdoughs inoculated with a co-culture containing above $5 \%(v / w)$ of $L$. paracasei ssp. paracasei MIUG BL 21 strain and up to $0.20 \%(v / w)$ of L. parabuchneri MIUG BL 24 strain. Similarly, the total inhibition is likely to be reached when a maximum of $1.10 \%(v / w)$, of L. paracasei ssp. paracasei MIUG BL 21 strain together with no more than $6.68 \%(v / w)$ of $L$. parabuchneri MIUG BL 24 strain inoculum was employed in the biotechnological process of the sourdough's SSF fermentation (Figure 3a,b). 
Furthermore, Bacillus spp. strain growth was totally inhibited by two formulated gluten-free sourdough samples: (i) the sample fermented by the co-culture containing at least $3.76 \%(v / w)$ of L. parabuchneri MIUG BL 24 strain and maximum $2.35 \%(v / w)$ of $L$. paracasei ssp. paracasei MIUG BL 21 strain, or (ii) the sourdough sample fermented with a minimum volume of $4.39 \%(v / w)$ of L. paracasei ssp. paracasei MIUG BL 21 strain combined with maximum $2.21 \%(v / w)$ of L. parabuchneri MIUG BL 24 strain (Figure 4a,b).

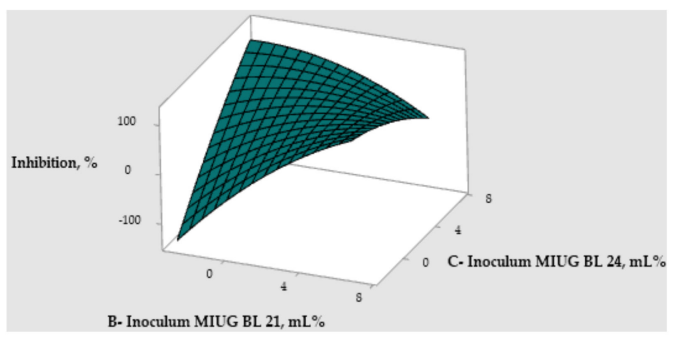

(a)

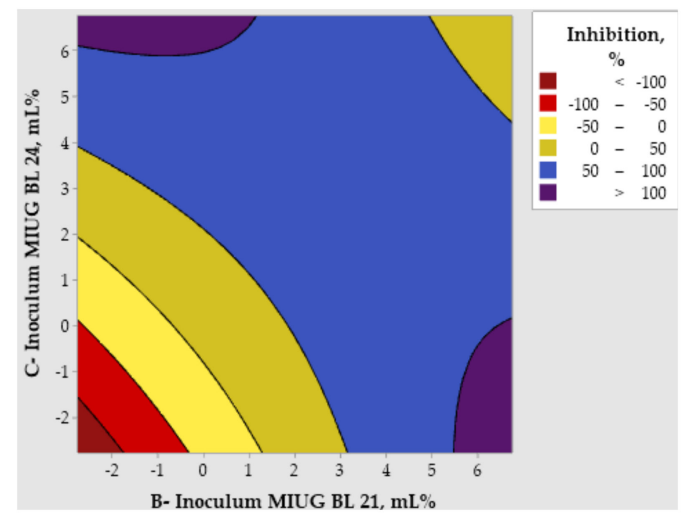

(b)

Figure 3. Surface (a) and contour (b) plots for the two-way interactions between the significant fermentation variables $B$ and $C$, on the antifungal activity (inhibition ratio, \%) against Penicillium spp. The mean of the factors $A$ to $F$ is given in Table 2.

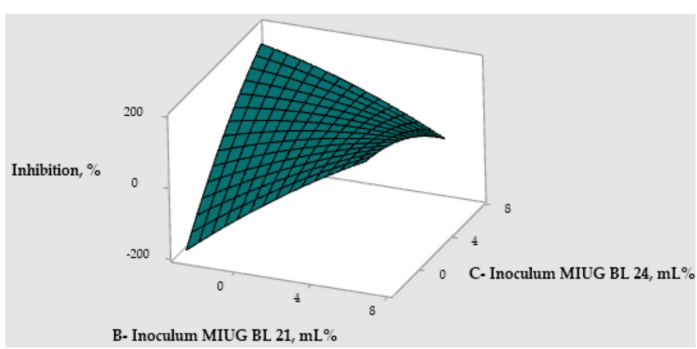

(a)

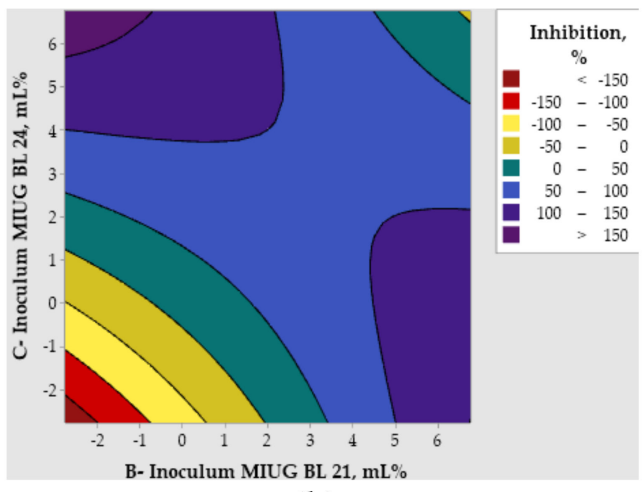

(b)

Figure 4. Surface (a) and contour (b) plots for the two-way interactions between the significant fermentation variables $B$ and $C$, on the antibacterial activity (inhibition ratio, \%) against Bacillus spp. The mean of the factors $A$ to $F$ is given in Table 2.

Resorting to the obtained experimental data, the following Equation (9) was attained for the antibacterial activity of the sourdoughs against Bacillus spp. strain as follows:

$$
\begin{gathered}
I, \%=-202.000+0.163 A+16.400 B+22.600 C-3.290 D+7.550 E+2.061 F-0.800 B^{2}-1.390 C^{2}- \\
0.108 D^{2}-0.096 E^{2}-0.006 F^{2}+0.027 A B+0.001 A D+0.001 A E-5.720 B C-0.315 B D-0.203 B E+ \\
0.032 B F+0.585 C D-0.064 C E+0.070 C F+0.069 D E+0.014 D F-0.031 E F / /
\end{gathered}
$$

It can be concluded that each selected starter culture has a different fermentation behavior when composed of a co-culture of these LAB strains (Figure 4). Additionally, the inoculum size possesses a strong influence on the fermented product's composition and properties.

Different culture medium constituents, fermentation temperatures and incubation times or inoculum sizes were screened via Plackett-Burman Design (PBD), Response Surface Methodology (RSM) or Box-Behnken Design (BBD) to identify the most suitable conditions for the specific enzyme biosynthesis $[63,74]$. The statistical studies for the 
process optimization are very common in food science and other biotechnological fields, to decrease the number of time-consuming experimental runs, costs and technical resources. In particular, various factors were screened by PBD and RSM in order to establish those with significant effects on the TTA levels of a sourdough fermented with $L$. paracasei ssp. paracasei [75]. A stable matrix able to ensure the L. curvatus viability during storage was optimized by RSM, being successfully used in the sourdough technology [76]. Moreover, the variation of the dough yield between 175-225 was statistically studied to conclude that this factor positively affects the textural characteristics of a sourdough cake [77]. Sourdough bread's physicochemical and textural properties (viz. TTA, porosity, chewiness and hardness) were optimized after the RSM analysis by Abedfar et al. (2019) [78]. The regression coefficients reported in the above-mentioned study varied between $43.4-97.9 \%$ and $29.5-95.2 \%$ for $R^{2}$ and adjusted $R^{2}\left(R^{2}\right.$ adj), respectively. In our RSM analyses, values in the same range were attained (viz. $R^{2} 71.4-87.7 \%$ and $R^{2}$ adj $40.4-74.4 \%$ ).

The antifungal effect of LAB metabolites has been intensively studied by several researchers to conclude that the fungal growth is related to multiple biotechnological factors. The most important factors have been claimed to be the type of exogenous LAB starter strains used for fermentation and their initial concentration. Aspergillus flavus, Aspergillus niger and Aspergillus tubingensis indicator strains were successfully inhibited by Lactobacillus spp. and Leuc. mesenteroides strains studied by Ouiddir et al. [67] and Çakır et al. [79]. In addition, the fungal contamination of bread by Penicillium spp. strains was delayed by 3 days when a whole wheat sourdough inoculated with selected strains of $L$. plantarum was used [56]. The same effect was observed when $30 \%(w / w)$ of a commercial sourdough was used [80] or essential oils from aromatic plants [81], respectively, when a mixture of eugenol-citral was added to the wheat bread doughs [82].

A delayed bacterial spoilage determined by Bacillus subtilis, B. cereus and B. licheniformis was observed after the in vitro assays using Lactobacillus spp. strains for the sourdough bread making $[79,83]$. Finally, the study conducted by Pereira et al. [84] led to the conclusion that bread ropy spoilage can be effectively delayed by up to 3 days when the moisture content and $\mathrm{pH}$ value are controlled. The scientific works mentioned above reinforce the LAB strains' effects that contribute to sustainability and innovation in the production of food and feed that positively affect quality of life [85]. Moreover, sustainable approaches were reported by some authors regarding the utilization of the microorganisms from the sourdough microbiota as starters for other fermentation processes, results with positive impact on the economic efficiency and diversification of the products $[86,87]$. Thus, the stabilized sourdoughs could be used as artisanal starters for the fermentation processes associated with the agrifood byproducts bio-valorization through multiple bioprocessing techniques (fermentations, bioconversions) that support the circular economy and the environmental protection $[88,89]$. Finally, the postbiotics produced by LAB have multiple implications in the food and feed preservation and safety assurance. The in vivo effects of the fermented products as a valuable source of biotics (prebiotics, postbiotics) are intensively studied regarding the health effects on both humans and animals, considering also the microbiome complexity and functionality [90].

In the current study, the RSM model was validated by the multi-response optimization tool, considering all the analyzed response variables (see Table 2). Based on the mathematical modelling studies, the following optimal combination of independent variables was established: 475.0 dough yield; co-inoculation of $2.9 \%(v / w)$ of L. paracasei ssp. paracasei MIUG BL 21 strain and 5.0\% (v/w) of L. parabuchneri MIUG BL 24 strain; 16.9\% $(w / w)$ of okara; $31.4^{\circ} \mathrm{C}$ fermentation temperature; and $66.1 \mathrm{~h}$ of fermentation time. The results for the considered responses under the optimized conditions are listed in Table 5. This optimized sourdough variant was experimentally produced, and the parameters analyzed. These experimental results excellently fit with the predicted ones (Table 5), as proved by the composite desirability (94\%) - which allowed the validation of the statistically optimized model [91]. Such value for the composite desirability is comparable to that of $98 \%$ obtained in a study for the formulation of gluten-free noodles [42]. 
Table 5. Predicted versus experimental results for the optimized sourdough. Inhibition ratios obtained according to Equation (2).

\begin{tabular}{lcc}
\hline \multicolumn{1}{c}{ Response } & Predicted Value & Experimental Value \\
\hline TTA, mL NaOH 0.1N & 33.12 & $40.21 \pm 2.16$ \\
Antifungal activity against Aspergillus niger I,\% & 70.20 & $71.42 \pm 1.00$ \\
Antifungal activity against Aspergillus flavus I,\% & 94.30 & $95.00 \pm 0.50$ \\
Antifungal activity against Penicillium spp. I,\% & 94.70 & $95.71 \pm 0.70$ \\
Antibacterial activity against Bacillus spp. I,\% & 100.00 & $100.00 \pm 0.00$ \\
Composite desirability & 0.94 & \\
\hline
\end{tabular}

Our results for the antimicrobial properties and TTA (Table 5) are in agreement to those reported in the literature. Particularly, inhibition ratios between 20 and $60 \%$ against Aspergillus spp. and Penicillium spp. indicator strains were determined for a chickpea sourdough [28], whereas a TTA value of 43.4 was obtained for a hemp sourdough fermented for $24 \mathrm{~h}$ at $30^{\circ} \mathrm{C}$ [92].

The satisfactory results, determined by the optimized gluten-free formulation from our work, suggest that this fermented product, obtained in controlled SSF fermentation conditions involving selected strains of $\mathrm{LAB}$, has valuable properties with impact on enhancing the antimicrobial and technological properties of the gluten-free sourdough bread that will be assessed in the future.

\subsection{The Organic Acids, Flavonoids and Polyphenolic Compounds Bioactive Composition of the Optimized Sourdough}

Under the optimal fermentation conditions, the resulting gluten-free sourdough was subjected to chromatographic analysis, by RP-HPLC-DAD, to investigate its profile of organic acids, flavonoids and polyphenolic compounds, as depicted in Figures 5-7. Following the established optimized variant, the LAB strains involved in the fermentation of the complex substrate made of chickpea, quinoa, buckwheat and okara increased the amount of lactic (peak 3) and propionic acids (peak 6), after $66 \mathrm{~h}$ of fermentation at $31.4{ }^{\circ} \mathrm{C}$ (Figure 5a), in comparison to the unfermented sample (Figure 5b). On the other hand, based on the peak's intensity, the optimized fermented sample showed a profile where a slight increase of the amount could be observed for the non-identified peaks 7 and 8 in Figure 5a, when compared to the same peaks in Figure 5b. Taking into consideration the organic acids that eluted from the fermented sourdough (Figure 5a), it can be stated that the mixed inoculum of the selected LAB starter used for fermentation displayed a heterofermentative metabolism that could increase the antimicrobial and technological features of baked goods [93].

A dairy product fermented by L. rhamnosus showed antimicrobial properties due to the acetic, lactic, citric, propionic and succinic acids synthesized in the fermented medium [94]. Additionally, malic, tartaric and fumaric acids were identified in a wheatsoybean sourdough fermented with different mixed starters of Lactobacillus spp. [95]. It is well-known that the amount and type of organic acids found after the fermentation of different matrices depend largely on the inoculum strain(s) and the composition of the fermentation substrate $[72,96]$. The relatively high level of organic acids eluted as peaks 1 and 2 in the unfermented sourdough (Figure $5 b$ ) proves that it originated from the flours, as it was reported in some works [97,98]. Indeed, the accumulation of organic acids in the pseudocereal and legume seeds is a stress adaptation to inadequate environmental conditions [99]. 


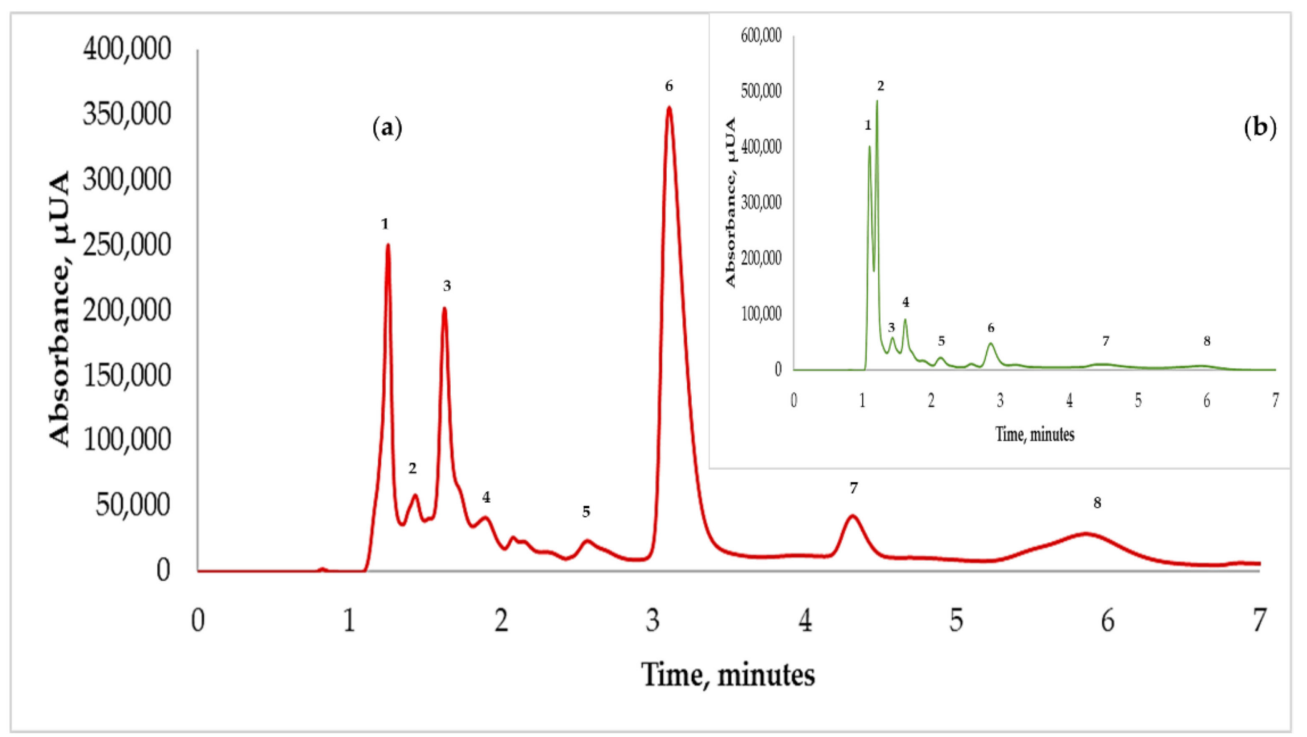

Figure 5. RP-HPLC-DAD $(\lambda=210 \mathrm{~nm})$ chromatograms for the organic acids in the optimized sourdough (a) and unfermented optimized sample (b), according to the elution pattern and chromatographic conditions described in Section 2.4. The injection volume (IV) was $20 \mu \mathrm{L}$ and the concentration of the sample was $400 \mathrm{mg} / \mathrm{mL}$. Peak's identification: 3-lactic acid; 5-acetic acid; 6-propionic acid.

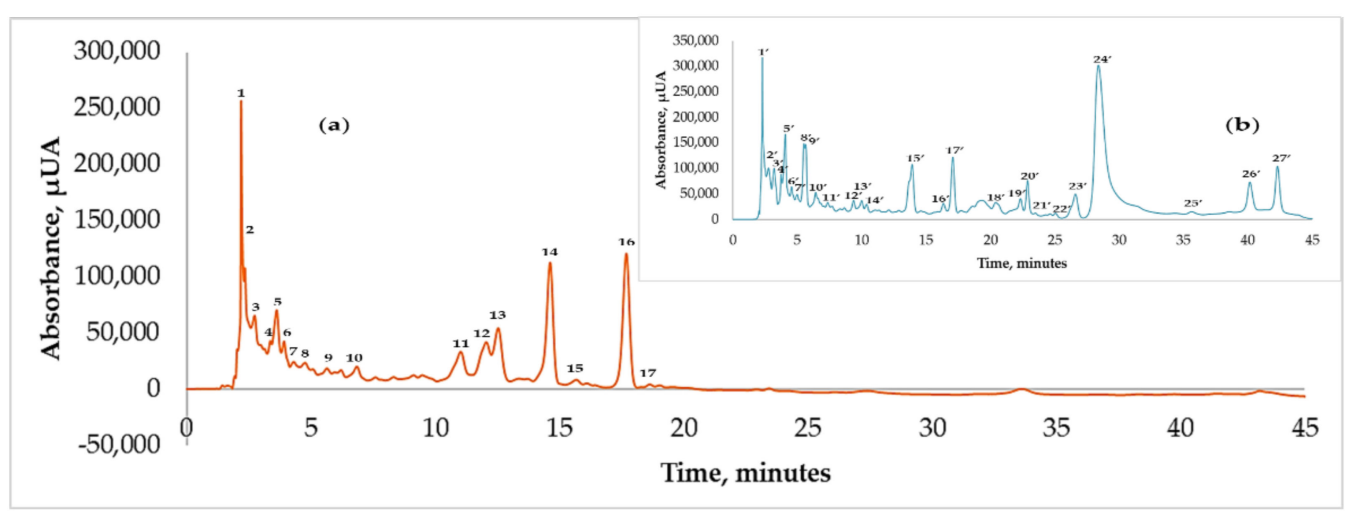

Figure 6. RP-HPLC-DAD $(\lambda=280 \mathrm{~nm})$ chromatograms for the flavonoids and polyphenols in the optimized sourdough (a), and the unfermented optimized dough (b), according to the elution pattern and the chromatographic conditions described in Section 2.4. The injection volume (IV) was $10 \mu \mathrm{L}$ and the concentration of the sample was $400 \mathrm{mg} / \mathrm{mL}$. Peak's identification: 9-caffeic acid; 10—vanillic acid; 12—ferulic acid; $8^{\prime}$ —chlorogenic acid; $9^{\prime}$ —caffeic acid; 10' —vanillic acid; 23' — quercetin; $24^{\prime}$ - gallic acid; $26^{\prime}$ - epicatechin.

The composition of the optimized gluten-free sourdough was also investigated by RP-HPLC-DAD and compared to the unfermented sourdough, to observe the differences in the composition of the most important bioactive compounds. The lactic acid fermentation process clearly modified the concentration of the flavonoids and polyphenols determined at wavelengths of $280 \mathrm{~nm}$ (Figure 6) and $320 \mathrm{~nm}$ (Figure 7), respectively. In the uninoculated sourdough sample, 27 bioactive compounds were separated (Figures $6 \mathrm{~b}$ and $7 \mathrm{~b}$ ), showing a higher diversity of these compounds when compared to the fermented sourdough (Figures $6 \mathrm{a}$ and $7 \mathrm{a}$ ). The gallic acid content was higher than quercetin in the unfermented sample (Figures $6 \mathrm{~b}$ and $7 \mathrm{~b}$ ). In contrast, more than 10 flavonoids and polyphenols can be observed in the chromatograms presented in Figures 6a and 7a. In the fermented optimized sourdough, only some bioactive compounds with the highest peaks' intensity could be separated from the baseline. The peaks' intensities corresponding to caffeic and vanillic acids were higher in the control sample, their maximum absorbances being identified at $280 \mathrm{~nm}$. On the other hand, ferulic acid was eluted at its maximum intensity in the fermented sourdough when the wavelength of $320 \mathrm{~nm}$ was used. The high number of 
peaks eluted between 4-19 min (Figure 6a), corresponding to ferulic, gallic, cinnamic acid or quercetin derivatives, that were the effect of the metabolic activities of the selected $\mathrm{LAB}$ used as starter cultures, were preliminarily identified by comparing the retention times to those reported in the literature $[100,101]$. Similarly, in the unfermented sample (Figure 6b), the $p$-coumaric acid (peak $11^{\prime}$ ), vanillic (peak $12^{\prime}$ ) and caffeic acid (peak $16^{\prime}$ ) derivatives were identified [102,103]. The acidic conditions of the fermented medium and other microbial enzymes may significantly affect the composition of flavonoids and polyphenols in the final sourdough, thus resulting in structural changes. Another reason for this difference between the uninoculated and fermented sourdoughs can be related to the ratio between the bounded and free phenolic compounds and flavonoids, the first ones being more stable. The concentration of the phenolic acids in some gluten-free cereals was studied by Zeng et al. [104] using HPLC methods, to conclude that the content of bounded phenolic acids was higher than the free phenolics.

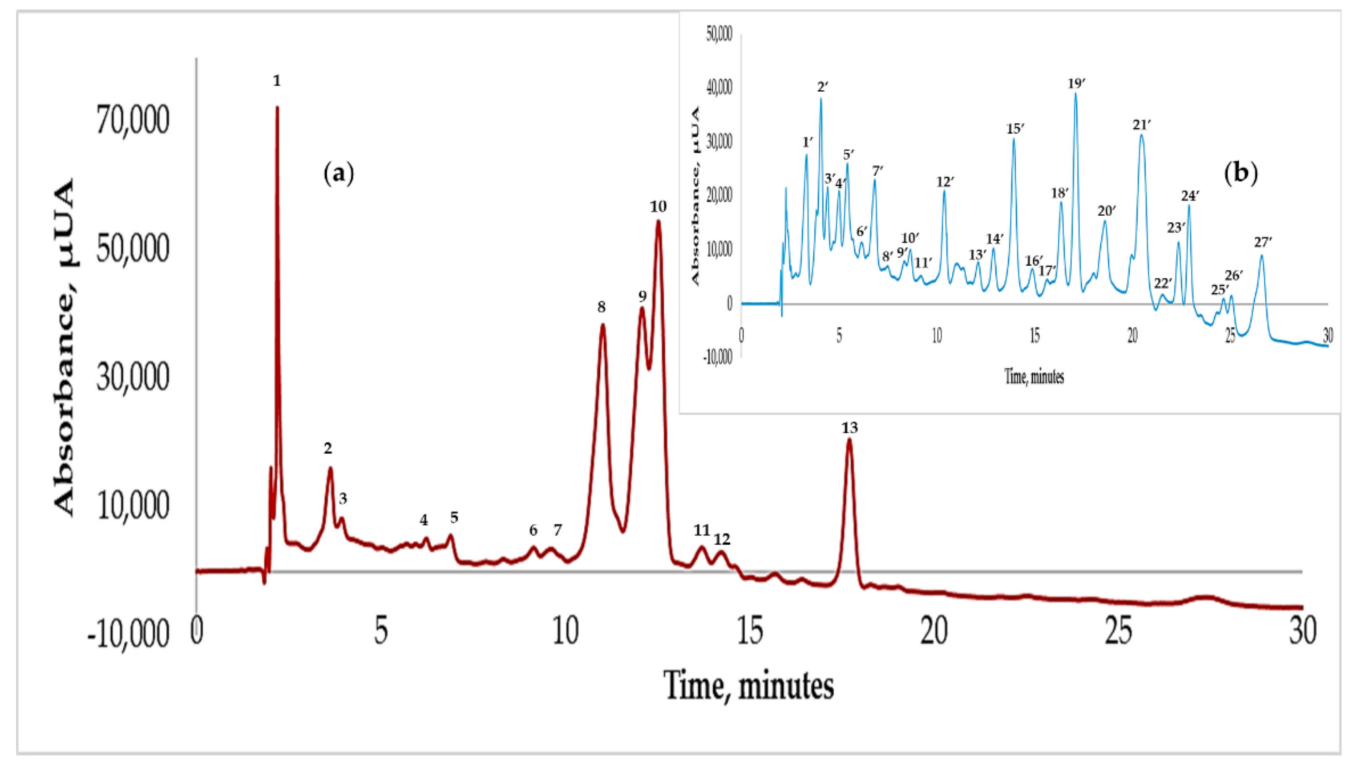

Figure 7. RP-HPLC-DAD $(\lambda=320 \mathrm{~nm})$ chromatograms for the flavonoids and polyphenols in the optimized sourdough (a), and the unfermented optimized dough (b), according to the elution pattern and the chromatographic conditions described in Section 2.4. The injection volume (IV) was $10 \mu \mathrm{L}$ and the concentration of the sample was $400 \mathrm{mg} / \mathrm{mL}$. Peak's identification: 4—vanillic acid; 9—ferulic acid; 5' — chlorogenic acid; $7^{\prime}$ —vanillic acid; $13^{\prime}$ —ferulic acid; $23^{\prime}$ — quercetin, $24^{\prime}$ —gallic acid.

Flavonoids (quercetin, catechin and kaempferol), tannins (proantocyanidins), phenolic acids (caffeic, chlorogenic, ferulic, gallic, vanillic) and their derivatives were identified in buckwheat $[105,106]$, quinoa, and chickpea seeds [107-109]. The intensity of each compound is different based on the wavelength used for the HPLC data acquisition [110], our results being supported by these above-mentioned works.

The antioxidant properties of pseudocereals and legumes are related to the applied processing methods [111,112]. Consequently, it was highlighted by Han et al. [113] that the levels of saponins and antinutritional factors depend on the milling process of quinoa. Furthermore, the antioxidant properties of buckwheat were modified after ultrasound treatment [114] whereas the importance of the HPLC elution solvent (acetonitrile) for the extraction of isoflavones from okara was stated by Nile et al. [115].

Jiang et al. [116] and Zhang et al. [117] affirmed that the molecular complexes between bioactive compounds and starch or proteins from flours can be formed in food systems, and their stability and properties are affected mainly by the $\mathrm{pH}$, temperature and nutritional composition of the matrix $[118,119]$. The above-mentioned conclusion would probably be the reason why the bioactive composition of our samples was different, along with the fact that the fermentation substrate was obtained by combining several flours, with different biologically active compound profiles. 
Finally, it is obvious that different chromatographic profiles of the fermented optimized sourdough and control sample (unfermented sourdough) were obtained in this work, such changes being justified by the specific metabolic activity of the selected LAB strains co-culture (L. paracasei ssp. paracasei MIUG BL 21 strain and L. parabuchneri MIUG BL 24 strain), in correlation with intrinsic and extrinsic factors' variation, under the optimized fermentation conditions established by RSM. Some researchers found that Lactobacillus spp. strains can synthesize enzymes (oxidases, esterases, decarboxylases and dehydrogenases) able to destabilize specific complexes and affect the individual structures of the polyphenolic compounds [120,121].

These results confirm that, by RSM, the interactions between the previously selected independent variables were established in order to determine the optimal conditions to achieve a gluten-free sourdough with enhanced antimicrobial properties against spoilage molds and bacteria, correlated to the organic acids content, phenolic content and functional properties.

\section{Conclusions}

The most important biotechnological parameters for an unconventional gluten-free sourdough obtained by a controlled solid-state fermentation process were analyzed through the mathematical modelling and statistical analysis support offered by Plackett-Burman Design and Response Surface Methodology tools.

Starting from a complex sterile substrate composition based on chickpea, quinoa, and buckwheat flours supplemented with okara (the solid residue of soymilk preparation), using as starter cultures the previously selected strains (three lactobacilli and a Leu. mesenteroides ssp. mesenteroides, respectively) and by varying the fermentation conditions according to the established design of the experiments, the most important parameters which impacted the fermented product's characteristics were determined. It was demonstrated that, following the designed biotechnological conditions, the variables with significant effects on the sourdough preparation are: the dough yield, L. paracasei ssp. paracasei MIUG BL 21 and L. parabuchneri MIUG BL 24 strains' inoculum type and size, the amount of okara, the temperature and the time of fermentation, respectively. As such, the proposed fermentation parameters for the optimal sourdough's production established by RSM analysis are: the dough yield $475.0,16.9 \%(w / w)$ okara, $2.9 \%(v / w)$ L. paracasei ssp. paracasei MIUG BL 21 strain inoculum, 5.0\% (v/w) L. parabuchneri MIUG BL 24 strain inoculum, $66.1 \mathrm{~h}$ of fermentation at $31.4{ }^{\circ} \mathrm{C}$.

The synergistic effect of the starter co-culture of L. paracasei ssp. paracasei MIUG BL 21 and L. parabuchneri MIUG BL 24 strains act in the controlled fermentation conditions towards the conversion of the flour's constituents into the desired postbiotics, mainly organic acids, flavonoids, polyphenols and their derivatives, with a great impact on the antimicrobial properties. The bioactive content and the antimicrobial properties of the optimized sourdough are valuable advantages to recommend this product as a bioingredient for food or feed formulations in order to improve their microbiological stability.

Supplementary Materials: The following are available online at https://www.mdpi.com/article/10.339 0/app11115306/s1, Table S1: ANOVA for the Total Titratable Acidity (TTA, mL NaOH 0.1N) from the PBD. The meaning of the factors $A$ to $H$ is given in Table 1; Table S2: ANOVA for the antifungal activity of the sourdoughs, measured as the inhibition effect ( $I$, \%, Equation (2)), against Aspergillus niger from the PBD. The meaning of the factors $A$ to $H$ is given in Table 1; Table S3: ANOVA for the sourdoughs' antifungal activity, measured as the inhibition effect (I, \%, Equation (2)), against Aspergillus flavus from the PBD. The meaning of the factors $A$ to $H$ is given in Table 1; Table S4: ANOVA for the sourdoughs' antifungal activity, measured as the inhibition effect ( $I, \%$, Equation (2)), against Penicillium spp. from the PBD. The meaning of the factors $A$ to $H$ is given in Table 1; Table S5: ANOVA for the sourdoughs' antibacterial activity, measured as the inhibition effect (I, \%, Equation (2)), against Bacillus spp. from the PBD. The meaning of the factors $A$ to $H$ is given in Table 1; Table S6: ANOVA for the Total TitratableAcidity (TTA, mL NaOH $0.1 \mathrm{~N}$ ), antifungal activity of the sourdoughs against Aspergillus niger, Aspergillus flavus 
and Penicillium spp., and antibacterial activity against Bacillus spp., measured as inhibition effect (I, \%, Equation (2)) from RSM. The meaning of the factors $A$ to $F$ is given in Table 2.

Author Contributions: Conceptualization. B.P.-B. and G.-E.B.; investigation. B.P.-B. and M.T.; writing-original draft preparation. B.P.-B.; writing-review and editing. G.-E.B. and J.M.R. All authors have read and agreed to the published version of the manuscript.

Funding: The work of Bogdan Păcularu-Burada was supported by the project ANTREPRENORDOC, in the framework of Human Resources Development, Operational Programme 2014-2020, financed from the European Social Fund under the contract number 36355/23.05.2019 HRD OP/380/6/13 SMIS Code: 123847.

Institutional Review Board Statement: Not applicable.

Informed Consent Statement: Not applicable.

Data Availability Statement: Not applicable.

Acknowledgments: This work is part of a grant of the Ministry of Research, Innovation and Digitization, CNCS/CCCDI-UEFISCDI, project number PCE 159/2021, within PNCDI III and is also corelated with the activities of the COST Action 18101 SOURDOMICS—Sourdough biotechnology network towards novel, healthier and sustainable food and bioprocesses (https:/ / sourdomics.com/; https: / /www.cost.eu/actions/CA18101/, accessed on 20 April 2021).

Conflicts of Interest: The authors declare no conflict of interest.

\section{References}

1. Arora, K.; Ameur, H.; Polo, A.; Di Cagno, R.; Rizzello, C.G.; Gobbetti, M. Thirty years of knowledge on sourdough fermentation: A systematic review. Trends Food Sci. Technol. 2021, 108. [CrossRef]

2. Gobbetti, M.; De Angelis, M.; Di Cagno, R.; Polo, A.; Rizzello, C.G. The sourdough fermentation is the powerful process to exploit the potential of legumes, pseudo-cereals and milling by-products in baking industry. Crit. Rev. Food Sci. Nutr. 2020, 60, 2158-2173. [CrossRef] [PubMed]

3. Novotni, D.; Gänzle, M.; Rocha, J.M. Composition and activity of microbiota in sourdough and their effect on bread quality and safety. In Trends in Wheat and Bread Making; Galanakis, C.M., Ed.; Elsevier: Amsterdam, The Netherlands, 2021; pp. 129-172. ISBN 9780128210482.

4. Sakandar, H.A.; Hussain, R.; Kubow, S.; Sadiq, F.A.; Huang, W.; Imran, M. Sourdough bread: A contemporary cereal fermented product. J. Food Process. Preserv. 2019, 43, e13883. [CrossRef]

5. Diowksz, A.; Malik, A.; Jásniewska, A.; Leszczyńska, J.; Jaśniewska, A.; Leszczyńska, J.; Jásniewska, A.; Leszczyńska, J. The inhibition of amylase and ACE enzyme and the reduction of immunoreactivity of sourdough bread. Foods 2020, 9, 656. [CrossRef] [PubMed]

6. Mantziari, A.; Salminen, S.; Szajewska, H.; Malagón-Rojas, J.N. Postbiotics against Pathogens Commonly Involved in Pediatric Infectious Diseases. Microorganisms 2020, 8, 1510. [CrossRef]

7. Davani-Davari, D.; Negahdaripour, M.; Karimzadeh, I.; Seifan, M.; Mohkam, M.; Masoumi, S.; Berenjian, A.; Ghasemi, Y. Prebiotics: Definition, Types, Sources, Mechanisms, and Clinical Applications. Foods 2019, 8, 92. [CrossRef]

8. Żółkiewicz, J.; Marzec, A.; Ruszczyński, M.; Feleszko, W. Postbiotics-A Step Beyond Pre-and Probiotics. Nutrients 2020, 12, 2189. [CrossRef]

9. Barros, C.P.; Guimarães, J.T.; Esmerino, E.A.; Duarte, M.C.K.; Silva, M.C.; Silva, R.; Ferreira, B.M.; Sant'Ana, A.S.; Freitas, M.Q.; Cruz, A.G. Paraprobiotics and postbiotics: Concepts and potential applications in dairy products. Curr. Opin. Food Sci. 2020, 32, 1-8. [CrossRef]

10. Menezes, L.A.A.; Sardaro, M.L.S.; Duarte, R.T.D.; Mazzon, R.R.; Neviani, E.; Gatti, M.; De Dea Lindner, J. Sourdough bacterial dynamics revealed by metagenomic analysis in Brazil. Food Microbiol. 2020, 85, 103302. [CrossRef]

11. Bartkiene, E.; Lele, V.; Ruzauskas, M.; Domig, K.J.; Starkute, V.; Zavistanaviciute, P.; Bartkevics, V.; Pugajeva, I.; Klupsaite, D.; Juodeikiene, G.; et al. Lactic Acid Bacteria Isolation from Spontaneous Sourdough and Their Characterization Including Antimicrobial and Antifungal Properties Evaluation. Microorganisms 2019, 8, 64. [CrossRef] [PubMed]

12. Moradi, M.; Molaei, R.; Guimarães, J.T. A review on preparation and chemical analysis of postbiotics from lactic acid bacteria. Enzym. Microb. Technol. 2021, 143, 109722. [CrossRef] [PubMed]

13. Vallejo-Cordoba, B.; Castro-López, C.; García, H.S.; González-Córdova, A.F.; Hernández-Mendoza, A. Postbiotics and paraprobiotics: A review of current evidence and emerging trends. In Advances in Food and Nutrition Research; Academic Press Inc.: Cambridge, MA, USA, 2020; Volume 94, pp. 1-34. ISBN 9780128202180.

14. Reale, A.; Di Renzo, T.; Preziuso, M.; Panfili, G.; Cipriano, L.; Messia, M.C. Stabilization of sourdough starter by spray drying technique: New breadmaking perspective. LWT Food Sci. Technol. 2019, 99, 468-475. [CrossRef] 
15. Caglar, N.; Ermis, E.; Durak, M.Z. Spray-dried and freeze-dried sourdough powders: Properties and evaluation of their use in breadmaking. J. Food Eng. 2021, 292, 110355. [CrossRef]

16. Rizzello, C.G.; Portincasa, P.; Montemurro, M.; Di Palo, D.M.; Lorusso, M.P.; De Angelis, M.; Bonfrate, L.; Genot, B.; Gobbetti, M. Sourdough Fermented Breads are More Digestible than Those Started with Baker's Yeast Alone: An In Vivo Challenge Dissecting Distinct Gastrointestinal Responses. Nutrients 2019, 11, 2954. [CrossRef]

17. Silow, C.; Axel, C.; Zannini, E.; Arendt, E.K. Application of sourdough in the production of fat- and salt-reduced puff pastry. Eur. Food Res. Technol. 2018, 244, 1581-1593. [CrossRef]

18. Clement, H.; Prost, C.; Rannou, C.; Chiron, H.; Bonnand-Ducasse, M.; Courcoux, P.; Onno, B. Can instrumental characterization help predicting sour taste perception of wheat sourdough bread? Food Res. Int. 2020, 133, 109159. [CrossRef] [PubMed]

19. Seo, K.-H.; Jeong, J.; Kim, H. Synergistic Effects of Heat-Killed Kefir Paraprobiotics and Flavonoid-Rich Prebiotics on Western Diet-Induced Obesity. Nutrients 2020, 12, 2465. [CrossRef] [PubMed]

20. Popescu, R.G.; Popescu, G.N. An Exploratory Study Based on a Questionnaire Concerning Green and Sustainable Finance, Corporate Social Responsibility, and Performance: Evidence from the Romanian Business Environment. J. Risk Financ. Manag. 2019, 12, 162. [CrossRef]

21. Cazares, M.; Andrade, R.O.; Proaño, J.; Ortiz, I. Study of Technological Solutions in the Analysis of Behavioral Factors for Sustainability Strategies. In Sustainable Intelligent Systems: Advances in Sustainability Science and Technology; Joshi, A., Nagar, A.K., Marín-Raventós, G., Eds.; Springer: Singapore, 2021; pp. 175-188.

22. Mesquita dos Santos, M.C.; Leandro, E.d.S.; Rodrigues de Alencar, E.; Assunção Botelho, R.B. Fermentation of chickpea (Cicer arietinum L.) and coconut (Coccus nucifera L.) beverages by Lactobacillus paracasei subsp paracasei LBC 81: The influence of sugar content on growth and stability during storage. LWT Food Sci. Technol. 2020, 132, 109834. [CrossRef]

23. Aguilar, J.; Miano, A.C.; Obregón, J.; Soriano-Colchado, J.; Barraza-Jáuregui, G. Malting process as an alternative to obtain high nutritional quality quinoa flour. J. Cereal Sci. 2019, 90, 102858. [CrossRef]

24. Dakhili, S.; Abdolalizadeh, L.; Hosseini, S.M.; Shojaee-Aliabadi, S.; Mirmoghtadaie, L. Quinoa protein: Composition, structure and functional properties. Food Chem. 2019, 299, 125161. [CrossRef]

25. Skendi, A.; Zinoviadou, K.G.; Papageorgiou, M.; Rocha, J.M. Advances on the Valorisation and Functionalization of By-Products and Wastes from Cereal-Based Processing Industry. Foods 2020, 9, 1243. [CrossRef] [PubMed]

26. Guardado-Félix, D.; Lazo-Vélez, M.A.; Pérez-Carrillo, E.; Panata-Saquicili, D.E.; Serna-Saldívar, S.O. Effect of partial replacement of wheat flour with sprouted chickpea flours with or without selenium on physicochemical, sensory, antioxidant and protein quality of yeast-leavened breads. LWT Food Sci. Technol. 2020, 129, 109517. [CrossRef]

27. Motta, C.; Castanheira, I.; Gonzales, G.B.; Delgado, I.; Torres, D.; Santos, M.; Matos, A.S. Impact of cooking methods and malting on amino acids content in amaranth, buckwheat and quinoa. J. Food Compos. Anal. 2019, 76, 58-65. [CrossRef]

28. Schettino, R.; Pontonio, E.; Gobbetti, M.; Rizzello, C.G. Extension of the Shelf-Life of Fresh Pasta Using Chickpea Flour Fermented with Selected Lactic Acid Bacteria. Microorganisms 2020, 8, 1322. [CrossRef]

29. Carrizo, S.L.; de Moreno de LeBlanc, A.; Guy LeBlanc, J.; Rollán, G.C. Quinoa pasta fermented with lactic acid bacteria prevents nutritional deficiencies in mice. Food Res. Int. 2020, 127, 108735. [CrossRef]

30. Suárez-Estrella, D.; Cardone, G.; Buratti, S.; Pagani, M.A.; Marti, A. Sprouting as a pre-processing for producing quinoa-enriched bread. J. Cereal Sci. 2020, 96, 103111. [CrossRef]

31. Boyaci Gunduz, C.P.; Gaglio, R.; Franciosi, E.; Settanni, L.; Erten, H. Molecular analysis of the dominant lactic acid bacteria of chickpea liquid starters and doughs and propagation of chickpea sourdoughs with selected Weissella confusa. Food Microbiol. 2020, 91, 103490. [CrossRef]

32. Păcularu-Burada, B.; Georgescu, L.A.; Bahrim, G.-E. Current approaches in sourdough production with valuable characteristics for technological and functional applications. Ann. Univ. Dunarea Jos Galati Fascicle VI Food Technol. 2020, 44, 132-148. [CrossRef]

33. Hu, Y.; Piao, C.; Chen, Y.; Zhou, Y.; Wang, D.; Yu, H.; Xu, B. Soybean residue (okara) fermentation with the yeast Kluyveromyces marxianus. Food Biosci. 2019, 31, 100439. [CrossRef]

34. Wang, X.; Zhang, Y.; Li, Y.; Yu, H.; Wang, Y.; Piao, C. Insoluble dietary fibre from okara (soybean residue) modified by yeast Kluyveromyces marxianus. LWT Food Sci. Technol. 2020, 134, 110252. [CrossRef]

35. Shi, H.; Zhang, M.; Wang, W.; Devahastin, S. Solid-state fermentation with probiotics and mixed yeast on properties of okara. Food Biosci. 2020, 36, 100610. [CrossRef]

36. Quintana, G.; Spínola, V.; Martins, G.N.; Gerbino, E.; Gómez-Zavaglia, A.; Castilho, P.C. Release of health-related compounds during in vitro gastro-intestinal digestion of okara and okara fermented with Lactobacillus plantarum. J. Food Sci. Technol. 2020, 57, 1061-1070. [CrossRef]

37. Castellanos Fuentes, A.P.; Genevois, C.E.; Flores, S.K.; de Escalada Pla, M.F. Valorisation of soy by-products as substrate for food ingredients containing L. casei through solid state fermentation. LWT Food Sci. Technol. 2020, 132, 109779. [CrossRef]

38. Xavier-Santos, D.; Bedani, R.; Lima, E.D.; Saad, S.M.I. Impact of probiotics and prebiotics targeting metabolic syndrome. J. Funct. Foods 2020, 64, 103666. [CrossRef]

39. Zheng, J.; Wittouck, S.; Salvetti, E.; Franz, C.M.A.P.; Harris, H.M.B.; Mattarelli, P.; O’Toole, P.W.; Pot, B.; Vandamme, P.; Walter, J.; et al. A taxonomic note on the genus Lactobacillus: Description of 23 novel genera, emended description of the genus Lactobacillus Beijerinck 1901, and union of Lactobacillaceae and Leuconostocaceae. Int. J. Syst. Evol. Microbiol. 2020, 70, 2782-2858. [CrossRef] 
40. Ma, L.; Wang, L.; Tang, J.; Yang, Z. Optimization of arsenic extraction in rice samples by Plackett-Burman design and response surface methodology. Food Chem. 2016, 204, 283-288. [CrossRef] [PubMed]

41. Zhao, Y.; Kweon, M. Formula optimization of ready-to-proof and ready-to-bake frozen dough of sweet bread using response surface methodology. LWT Food Sci. Technol. 2020, 139, 110581. [CrossRef]

42. Wangtueai, S.; Phimolsiripol, Y.; Vichasilp, C.; Regenstein, J.M.; Schoenlechner, R.; Schöenlechner, R. Optimization of gluten-free functional noodles formulation enriched with fish gelatin hydrolysates. LWT Food Sci. Technol. 2020, 133, 109977. [CrossRef]

43. Miranda-Ramos, K.C.; Haros, C.M. Combined Effect of Chia, Quinoa and Amaranth Incorporation on the Physico-Chemical, Nutritional and Functional Quality of Fresh Bread. Foods 2020, 9, 1859. [CrossRef] [PubMed]

44. Voinea, A.; Stroe, S.-G.; Codină, G.G. The Effect of Sodium Reduction by Sea Salt and Dry Sourdough Addition on the Wheat Flour Dough Rheological Properties. Foods 2020, 9, 610. [CrossRef]

45. Păcularu-Burada, B.; Georgescu, L.A.; Vasile, M.A.; Rocha, J.M.; Bahrim, G.-E. Selection of Wild Lactic Acid Bacteria Strains as Promoters of Postbiotics in Gluten-Free Sourdoughs. Microorganisms 2020, 8, 643. [CrossRef]

46. Tamang, B.; Tamang, J.P.; Schillinger, U.; Franz, C.M.A.P.; Gores, M.; Holzapfel, W.H. Phenotypic and genotypic identification of lactic acid bacteria isolated from ethnic fermented bamboo tender shoots of North East India. Int. J. Food Microbiol. 2008, 121, 35-40. [CrossRef] [PubMed]

47. Yi, H.; Zhang, L.; Han, X.; Du, M.; Zhang, Y.; Li, J.; Sun, K.; Hou, Y. Isolation and applied potential of lactic acid bacteria from Chinese traditional fermented food in specific ecological localities. Food Sci. Biotechnol. 2011, 20, 1685-1690. [CrossRef]

48. Zeng, Z.; Lin, J.; Gong, D. Identification of lactic acid bacterial strains with high conjugated linoleic acid-producing ability from natural sauerkraut fermentations. J. Food Sci. 2009, 74, M154-M158. [CrossRef] [PubMed]

49. Lei, W.; Liu, C.; Pan, L.; Peng, C.; Wang, J.; Zhou, H. Screening of probiotic Lactobacilli with potential anti-allergic activity based on hyaluronidase inhibition and degranulation of RBL-2H3 cells in vitro. LWT Food Sci. Technol. 2021, 140, 110707. [CrossRef]

50. Mocanu, G.-D.; Chirilă, A.C.; Vasile, A.M.; Andronoiu, D.G.; Nistor, O.-V.; Barbu, V.; Stănciuc, N. Tailoring the Functional Potential of Red Beet Purées by Inoculation with Lactic Acid Bacteria and Drying. Foods 2020, 9, 1611. [CrossRef] [PubMed]

51. Ayyash, M.; Johnson, S.K.; Liu, S.-Q.; Mesmari, N.; Dahmani, S.; Al Dhaheri, A.S.; Kizhakkayil, J. In vitro investigation of bioactivities of solid-state fermented lupin, quinoa and wheat using Lactobacillus spp. Food Chem. 2019, 275, 50-58. [CrossRef]

52. Franco, W.; Pérez-Díaz, I.; Connelly, L.; Diaz, J. Isolation of Exopolysaccharide-Producing Yeast and Lactic Acid Bacteria from Quinoa (Chenopodium Quinoa) Sourdough Fermentation. Foods 2020, 9, 337. [CrossRef]

53. Xie, C.; Coda, R.; Chamlagain, B.; Edelmann, M.; Varmanen, P.; Piironen, V.; Katina, K. Fermentation of cereal, pseudo-cereal and legume materials with Propionibacterium freudenreichii and Levilactobacillus brevis for vitamin B12 fortification. LWT Food Sci. Technol. 2021, 137, 110431. [CrossRef]

54. Comasio, A.; Van Kerrebroeck, S.; Harth, H.; Verté, F.; De Vuyst, L. Potential of Bacteria from Alternative Fermented Foods as Starter Cultures for the Production of Wheat Sourdoughs. Microorganisms 2020, 8, 1534. [CrossRef]

55. Jafari, S.M.; Ghanbari, V.; Dehnad, D.; Ganje, M. Improving the storage stability of tomato paste by the addition of encapsulated olive leaf phenolics and experimental growth modeling of A. flavus. Int. J. Food Microbiol. 2021, 338, 109018. [CrossRef] [PubMed]

56. Sun, L.; Li, X.; Zhang, Y.; Yang, W.; Ma, G.; Ma, N.; Hu, Q.; Pei, F. A novel lactic acid bacterium for improving the quality and shelf life of whole wheat bread. Food Control 2020, 109, 106914. [CrossRef]

57. Park, M.-J.; Kim, J.-H.; Oh, S.-W. Inactivation effect of UV-C and mild heat treatment against Salmonella Typhimurium and Escherichia coli O157:H7 on black pepper powder. Food Sci. Biotechnol. 2019, 28, 599-607. [CrossRef]

58. Ben Taheur, F.; Mansour, C.; Kouidhi, B.; Chaieb, K. Use of lactic acid bacteria for the inhibition of Aspergillus flavus and Aspergillus carbonarius growth and mycotoxin production. Toxicon 2019, 166, 15-23. [CrossRef]

59. Nionelli, L.; Wang, Y.; Pontonio, E.; Immonen, M.; Rizzello, C.G.G.; Maina, H.N.N.; Katina, K.; Coda, R. Antifungal effect of bioprocessed surplus bread as ingredient for bread-making: Identification of active compounds and impact on shelf-life. Food Control 2020, 118, 107437. [CrossRef]

60. Cotârleț, M.; Stănciuc, N.; Bahrim, G.E. Yarrowia lipolytica and Lactobacillus paracasei Solid State Fermentation as a Valuable Biotechnological Tool for the Pork Lard and Okara's Biotransformation. Microorganisms 2020, 8, 1098. [CrossRef]

61. Zhou, Q.; Gu, R.; Li, P.; Lu, Y.; Chen, L.; Gu, Q. Anti-Salmonella mode of action of natural l-phenyl lactic acid purified from Lactobacillus plantarum ZJ316. Appl. Microbiol. Biotechnol. 2020, 104, 5283-5292. [CrossRef]

62. Bouallegue, A.; Casillo, A.; Chaari, F.; Cimini, D.; Corsaro, M.M.; Bachoual, R.; Ellouz-Chaabouni, S. Statistical optimization of levan: Influence of the parameter on levan structure and angiotensin I-converting enzyme inhibitory. Int. J. Biol. Macromol. 2020, 158, 945-952. [CrossRef]

63. Karlapudi, A.P.; Krupanidhi, S.; Rajeswara Reddy, E.; Indira, M.; Bobby, M.N.; Venkateswarulu, T.C. Plackett-Burman design for screening of process components and their effects on production of lactase by newly isolated Bacillus sp. VUVD101 strain from Dairy effluent. Beni Suef Univ. J. Basic Appl. Sci. 2018, 7, 543-546. [CrossRef]

64. Xing, H.; Du, R.; Zhao, F.; Han, Y.; Xiao, H.; Zhou, Z. Optimization, chain conformation and characterization of exopolysaccharide isolated from Leuconostoc mesenteroides DRP105. Int. J. Biol. Macromol. 2018, 112, 1208-1216. [CrossRef]

65. Xu, Y.; Wang, Y.; Coda, R.; Säde, E.; Tuomainen, P.; Tenkanen, M.; Katina, K. In situ synthesis of exopolysaccharides by Leuconostoc spp. and Weissella spp. and their rheological impacts in fava bean flour. Int. J. Food Microbiol. 2017, 248, 63-71. [CrossRef] 
66. Montiel-Sánchez, M.; García-Cayuela, T.; Gómez-Maqueo, A.; García, H.S.; Pilar Cano, M. In vitro gastrointestinal stability, bioaccessibility and potential biological activities of betalains and phenolic compounds in cactus berry fruits (Myrtillocactus geometrizans). Food Chem. 2020, 342, 128087. [CrossRef]

67. Ouiddir, M.; Bettache, G.; Leyva Salas, M.; Pawtowski, A.; Donot, C.; Brahimi, S.; Mabrouk, K.; Coton, E.; Mounier, J. Selection of Algerian lactic acid bacteria for use as antifungal bioprotective cultures and application in dairy and bakery products. Food Microbiol. 2019, 82, 160-170. [CrossRef]

68. Siepmann, F.B.; Sousa de Almeida, B.; Waszczynskyj, N.; Spier, M.R. Influence of temperature and of starter culture on biochemical characteristics and the aromatic compounds evolution on type II sourdough and wheat bread. LWT Food Sci. Technol. 2019, 108, 199-206. [CrossRef]

69. Galli, V.; Venturi, M.; Pini, N.; Guerrini, S.; Granchi, L.; Vincenzini, M. Liquid and firm sourdough fermentation: Microbial robustness and interactions during consecutive backsloppings. LWT Food Sci. Technol. 2019, 105, 9-15. [CrossRef]

70. Yildirim, R.M.; Arici, M. Effect of the fermentation temperature on the degradation of phytic acid in whole-wheat sourdough bread. LWT Food Sci. Technol. 2019, 112, 108224. [CrossRef]

71. Galli, V.; Venturi, M.; Coda, R.; Maina, N.H.; Granchi, L. Isolation and characterization of indigenous Weissella confusa for in situ bacterial exopolysaccharides (EPS) production in chickpea sourdough. Food Res. Int. 2020, 138, 109785. [CrossRef] [PubMed]

72. Kuley, E.; Özyurt, G.; Özogul, I.; Boga, M.; Akyol, I.; Rocha, J.M.; Özogul, F. The Role of Selected Lactic Acid Bacteria on Organic Acid Accumulation during Wet and Spray-Dried Fish-Based Silages. Contributions to the Winning Combination of Microbial Food Safety and Environmental Sustainability. Microorganisms 2020, 8, 172. [CrossRef] [PubMed]

73. Aboukhalaf, A.; El Amraoui, B.; Tabatou, M.; da Rocha, J.M.F.; Belahsen, R. Screening of the antimicrobial activity of some extracts of edible wild plants in Morocco. Funct. Foods Health Dis. 2020, 10. [CrossRef]

74. Qadir, F.; Shariq, M.; Ahmed, A.; Sohail, M. Evaluation of a yeast co-culture for cellulase and xylanase production under solid state fermentation of sugarcane bagasse using multivariate approach. Ind. Crop. Prod. 2018, 123, 407-415. [CrossRef]

75. Cotârleț, M.; Maftei, N.M.; Bahrim, G.E. Increasing the fermentation efficiency of Lactobacillus paracasei ssp. paracasei MIUG BL6 in a rye flour sourdough. Turk. J. Biochem. 2019, 44, 307-315. [CrossRef]

76. Gul, L.B.; Con, A.H.; Gul, O. Storage stability and sourdough acidification kinetic of freeze-dried Lactobacillus curvatus N19 under optimized cryoprotectant formulation. Cryobiology 2020, 96, 122-129. [CrossRef] [PubMed]

77. Wu, Y.; Yan, B.; Zhou, J.; Lian, H.; Yu, X.; Zhao, J.; Zhang, H.; Chen, W.; Fan, D. Effects of sourdough on improving the textural characteristics of microwave-steamed cake: A perspective from dielectric properties and water distribution. J. Food Sci. 2020, 85. [CrossRef]

78. Abedfar, A.; Sadeghi, A. Response surface methodology for investigating the effects of sourdough fermentation conditions on Iranian cup bread properties. Heliyon 2019, 5, e02608. [CrossRef] [PubMed]

79. Çakır, E.; Arıcı, M.; Durak, M.Z. Biodiversity and techno-functional properties of lactic acid bacteria in fermented hull-less barley sourdough. J. Biosci. Bioeng. 2020, 130, 450-456. [CrossRef]

80. Debonne, E.; Van Schoors, F.; Maene, P.; Van Bockstaele, F.; Vermeir, P.; Verwaeren, J.; Eeckhout, M.; Devlieghere, F. Comparison of the antifungal effect of undissociated lactic and acetic acid in sourdough bread and in chemically acidified wheat bread. Int. J. Food Microbiol. 2020, 321, 108551. [CrossRef] [PubMed]

81. Skendi, A.; Katsantonis, D.N.; Chatzopoulou, P.; Irakli, M.; Papageorgiou, M. Antifungal Activity of Aromatic Plants of the Lamiaceae Family in Bread. Foods 2020, 9, 1642. [CrossRef]

82. Ju, J.; Xie, Y.; Yu, H.; Guo, Y.; Cheng, Y.; Chen, Y.; Ji, L.; Yao, W. Synergistic properties of citral and eugenol for the inactivation of foodborne molds in vitro and on bread. LWT Food Sci. Technol. 2020, 122, 109063. [CrossRef]

83. Fraberger, V.; Ammer, C.; Domig, K.J. Functional Properties and Sustainability Improvement of Sourdough Bread by Lactic Acid Bacteria. Microorganisms 2020, 8, 1895. [CrossRef]

84. Pereira, A.P.M.; Freire, L.L.; Alvarenga, V.O.; Crucello, A.; Morassi, L.L.P.; Silva, F.P.; Stradiotto, G.C.; Sant'Ana, A.S.; Freire, L.L.; Alvarenga, V.O.; et al. Occurrence and enumeration of rope-producing spore forming bacteria in flour and their spoilage potential in different bread formulations. LWT Food Sci. Technol. 2020, 133, 110108. [CrossRef]

85. Capozzi, V.; Fragasso, M.; Bimbo, F. Microbial Resources, Fermentation and Reduction of Negative Externalities in Food Systems: Patterns toward Sustainability and Resilience. Fermentation 2021, 7, 54. [CrossRef]

86. Li, H.; Fu, J.; Hu, S.; Li, Z.; Qu, J.; Wu, Z.; Chen, S. Comparison of the effects of acetic acid bacteria and lactic acid bacteria on the microbial diversity of and the functional pathways in dough as revealed by high-throughput metagenomics sequencing. Int. J. Food Microbiol. 2021, 346, 109168. [CrossRef] [PubMed]

87. Johansson, L.; Nikulin, J.; Juvonen, R.; Krogerus, K.; Magalhães, F.; Mikkelson, A.; Nuppunen-Puputti, M.; Sohlberg, E.; de Francesco, G.; Perretti, G.; et al. Sourdough cultures as reservoirs of maltose-negative yeasts for low-alcohol beer brewing. Food Microbiol. 2021, 94, 103629. [CrossRef] [PubMed]

88. Jiang, Y.; Zhang, Y.; Wang, S.; Wang, Z.; Liu, Y.; Hu, Z.; Zhan, X. Improved environmental sustainability and bioenergy recovery through pig manure and food waste on-farm co-digestion in Ireland. J. Clean. Prod. 2021, 280, 125034. [CrossRef]

89. Režek Jambrak, A.; Nutrizio, M.; Djekić, I.; Pleslić, S.; Chemat, F. Internet of Nonthermal Food Processing Technologies (IoNTP): Food Industry 4.0 and Sustainability. Appl. Sci. 2021, 11, 686. [CrossRef]

90. O'Connor, P.M.; Kuniyoshi, T.M.; Oliveira, R.P.; Hill, C.; Ross, R.P.; Cotter, P.D. Antimicrobials for food and feed; a bacteriocin perspective. Curr. Opin. Biotechnol. 2020, 61, 160-167. [CrossRef] 
91. Olamiti, G.; Takalani, T.K.; Beswa, D.; Jideani, A.I.O. Effect of malting and fermentation on colour, thermal properties, functional groups and crystallinity level of flours from pearl millet (Pennisetum glaucum) and sorghum (Sorghum bicolor). Heliyon 2020. [CrossRef]

92. Nionelli, L.; Montemurro, M.; Pontonio, E.; Verni, M.; Gobbetti, M.; Rizzello, C.G. Pro-technological and functional characterization of lactic acid bacteria to be used as starters for hemp (Cannabis sativa L.) sourdough fermentation and wheat bread fortification. Int. J. Food Microbiol. 2018, 279, 14-25. [CrossRef] [PubMed]

93. Moon, S.H.; Kim, C.R.; Chang, H.C. Heterofermentative lactic acid bacteria as a starter culture to control kimchi fermentation. LWT Food Sci. Technol. 2018, 88. [CrossRef]

94. Garnier, L.; Penland, M.; Thierry, A.; Maillard, M.-B.; Jardin, J.; Coton, M.; Leyva Salas, M.; Coton, E.; Valence, F.; Mounier, J. Antifungal activity of fermented dairy ingredients: Identification of antifungal compounds. Int. J. Food Microbiol. 2020, 322, 108574. [CrossRef] [PubMed]

95. Teleky, B.-E.; Martău, A.G.; Ranga, F.; Chețan, F.; Vodnar, D.C. Exploitation of Lactic Acid Bacteria and Baker's Yeast as Single or Multiple Starter Cultures of Wheat Flour Dough Enriched with Soy Flour. Biomolecules 2020, 10, 778. [CrossRef]

96. Buksa, K. Effect of pentoses, hexoses, and hydrolyzed arabinoxylan on the most abundant sugar, organic acid, and alcohol contents during rye sourdough bread production. Cereal Chem. 2020, 97. [CrossRef]

97. Song, J.; Yan, Y.; Wang, X.; Li, X.; Chen, Y.; Li, L.; Li, W. Characterization of fatty acids, amino acids and organic acids in three colored quinoas based on untargeted and targeted metabolomics. LWT Food Sci. Technol. 2021, 140, 110690. [CrossRef]

98. Mir, N.A.; Riar, C.S.; Singh, S. Nutritional constituents of pseudo cereals and their potential use in food systems: A review. Trends Food Sci. Technol. 2018, 75, 170-180. [CrossRef]

99. Jeon, J.; Kim, J.K.; Wu, Q.; Park, S.U. Effects of cold stress on transcripts and metabolites in tartary buckwheat (Fagopyrum tataricum). Environ. Exp. Bot. 2018, 155, 488-496. [CrossRef]

100. Gómez-Caravaca, A.M.; Iafelice, G.; Lavini, A.; Pulvento, C.; Caboni, M.F.; Marconi, E. Phenolic Compounds and Saponins in Quinoa Samples (Chenopodium quinoa Willd.) Grown under Different Saline and Nonsaline Irrigation Regimens. J. Agric. Food Chem. 2012, 60, 4620-4627. [CrossRef] [PubMed]

101. Karamać, M.; Gai, F.; Longato, E.; Meineri, G.; Janiak, M.A.; Amarowicz, R.; Peiretti, P.G. Antioxidant Activity and Phenolic Composition of Amaranth (Amaranthus caudatus) during Plant Growth. Antioxidants 2019, 8, 173. [CrossRef] [PubMed]

102. Chen, H.J.; Inbaraj, B.S.; Chen, B.H. Determination of phenolic acids and flavonoids in Taraxacum formosanum kitam by liquid chromatography-tandem mass spectrometry coupled with a post-column derivatization technique. Int. J. Mol. Sci. 2012, 13. [CrossRef]

103. Carrasco-Sandoval, J.; Rebolledo, P.; Peterssen-Fonseca, D.; Fischer, S.; Wilckens, R.; Aranda, M.; Henríquez-Aedo, K. A fast and selective method to determine phenolic compounds in quinoa (Chenopodium quinoa Will) seeds applying ultrasound-assisted extraction and high-performance liquid chromatography. Chem. Pap. 2021, 75. [CrossRef]

104. Zeng, Z.; Liu, C.; Luo, S.; Chen, J.; Gong, E. The profile and bioaccessibility of phenolic compounds in cereals influenced by improved extrusion cooking treatment. PLoS ONE 2016, 11. [CrossRef] [PubMed]

105. Huda, M.N.; Lu, S.; Jahan, T.; Ding, M.; Jha, R.; Zhang, K.; Zhang, W.; Georgiev, M.I.; Park, S.U.; Zhou, M. Treasure from garden: Bioactive compounds of buckwheat. Food Chem. 2021, 335, 127653. [CrossRef] [PubMed]

106. Francis Raguindin, P.; Adam Itodo, O.; Stoyanov, J.; Dejanovic, G.M.; Gamba, M.; Asllanaj, E.; Minder, B.; Bussler, W.; Metzger, B.; Muka, T.; et al. A systematic review of phytochemicals in oat and buckwheat. Food Chem. 2021, 338, 127982. [CrossRef]

107. Pereira, E.; Cadavez, V.; Barros, L.; Encina-Zelada, C.; Stojković, D.; Sokovic, M.; Calhelha, R.C.; Gonzales-Barron, U.; Ferreira, I.C.F.R. Chenopodium quinoa Willd. (quinoa) grains: A good source of phenolic compounds. Food Res. Int. 2020, 137, 109574. [CrossRef] [PubMed]

108. Balakrishnan, G.; Schneider, R.G. Quinoa flavonoids and their bioaccessibility during in vitro gastrointestinal digestion. J. Cereal Sci. 2020, 95, 103070. [CrossRef]

109. Farag, M.A.; Sharaf El-Din, M.G.; Aboul-Fotouh Selim, M.; Owis, A.I.; Abouzid, S.F. Mass spectrometry-based metabolites profiling of nutrients and anti-nutrients in major legume sprouts. Food Biosci. 2020, 39. [CrossRef]

110. Ferreyra, S.; Bottini, R.; Fontana, A. Tandem absorbance and fluorescence detection following liquid chromatography for the profiling of multiclass phenolic compounds in different winemaking products. Food Chem. 2021, 338. [CrossRef]

111. Dzah, C.S.; Duan, Y.; Zhang, H.; Serwah Boateng, N.A.; Ma, H. Latest developments in polyphenol recovery and purification from plant by-products: A review. Trends Food Sci. Technol. 2020, 99, 375-388. [CrossRef]

112. Chávez-González, M.L.; Sepúlveda, L.; Verma, D.K.; Luna-García, H.A.; Rodríguez-Durán, L.V.; Ilina, A.; Aguilar, C.N. Conventional and Emerging Extraction Processes of Flavonoids. Processes 2020, 8, 434. [CrossRef]

113. Han, Y.; Chi, J.; Zhang, M.; Zhang, R.; Fan, S.; Dong, L.; Huang, F.; Liu, L. Changes in saponins, phenolics and antioxidant activity of quinoa (Chenopodium quinoa willd) during milling process. LWT Food Sci. Technol. 2019, 114, 108381. [CrossRef]

114. Harasym, J.; Satta, E.; Kaim, U. Ultrasound Treatment of Buckwheat Grains Impacts Important Functional Properties of Resulting Flour. Molecules 2020, 25, 3012. [CrossRef] [PubMed]

115. Nile, S.H.; Nile, A.; Oh, J.-W.W.; Kai, G. Soybean processing waste: Potential antioxidant, cytotoxic and enzyme inhibitory activities. Food Biosci. 2020, 38, 100778. [CrossRef]

116. Jiang, C.; Chen, Y.; Ye, X.; Wang, L.; Shao, J.; Jing, H.; Jiang, C.; Wang, H.; Ma, C. Three flavanols delay starch digestion by inhibiting $\alpha$-amylase and binding with starch. Int. J. Biol. Macromol. 2021, 172. [CrossRef] 
117. Zhang, Q.; Cheng, Z.; Wang, Y.; Fu, L. Dietary protein-phenolic interactions: Characterization, biochemical-physiological consequences, and potential food applications. Crit. Rev. Food Sci. Nutr. 2020, 1-27. [CrossRef] [PubMed]

118. Ge, R.H.; Wang, H. Nutrient components and bioactive compounds in tartary buckwheat bran and flour as affected by thermal processing. Int. J. Food Prop. 2020, 23, 127-137. [CrossRef]

119. Eran Nagar, E.; Berenshtein, L.; Hanuka Katz, I.; Lesmes, U.; Okun, Z.; Shpigelman, A. The impact of chemical structure on polyphenol bioaccessibility, as a function of processing, cell wall material and pH: A model system. J. Food Eng. 2021, 289, 110304. [CrossRef]

120. Guo, X.; Guo, A.; Li, E. Biotransformation of two citrus flavanones by lactic acid bacteria in chemical defined medium. Bioprocess Biosyst. Eng. 2020, 44, 1-12. [CrossRef]

121. Piekarska-Radzik, L.; Klewicka, E. Mutual influence of polyphenols and Lactobacillus spp. bacteria in food: A review. Eur. Food Res. Technol. 2020, 247, 9-24. [CrossRef] 